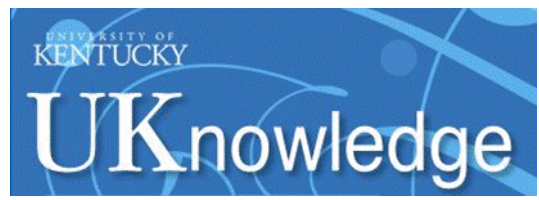

University of Kentucky

UKnowledge

Biosystems and Agricultural Engineering Faculty Publications

\title{
Performance Validation of a Multi-Channel LiDAR Sensor: Assessing the Effects of Target Height and Sensor Velocity on Measurement Error
}

\author{
Surya S. Dasika \\ University of Kentucky, surya.dasika@uky.edu \\ Michael P. Sama \\ University of Kentucky, michael.sama@uky.edu \\ L. Felipe Pampolini \\ University of Kentucky, Ifpampolini@icloud.com \\ Christopher B. Good \\ University of Kentucky
}

Follow this and additional works at: https://uknowledge.uky.edu/bae_facpub

Part of the Bioresource and Agricultural Engineering Commons

Right click to open a feedback form in a new tab to let us know how this document benefits you.

\section{Repository Citation}

Dasika, Surya S.; Sama, Michael P.; Pampolini, L. Felipe; and Good, Christopher B., "Performance Validation of a Multi-Channel LiDAR Sensor: Assessing the Effects of Target Height and Sensor Velocity on Measurement Error" (2019). Biosystems and Agricultural Engineering Faculty Publications. 249. https://uknowledge.uky.edu/bae_facpub/249

This Article is brought to you for free and open access by the Biosystems and Agricultural Engineering at UKnowledge. It has been accepted for inclusion in Biosystems and Agricultural Engineering Faculty Publications by an authorized administrator of UKnowledge. For more information, please contact UKnowledge@lsv.uky.edu. 


\section{Performance Validation of a Multi-Channel LiDAR Sensor: Assessing the Effects of Target Height and Sensor Velocity on Measurement Error}

\section{Digital Object Identifier (DOI)}

https://doi.org/10.13031/trans.12971

Notes/Citation Information

Published in Transactions of the ASABE, v. 62, issue 1.

@ 2019 American Society of Agricultural and Biological Engineers

The copyright holder has granted the permission for posting the article here.

The document available for download is the authors' post-peer-review final draft of the article. 


\title{
Performance VAlidation of a Multi-Channel LidAR SENSOR: ASSESSING THE EFFECT OF TARGET HEIGHT AND SENSOR VELOCITY ON MEASUREMENT ERROR
}

\author{
Saket S. Dasika, Michael P. Sama, L. Felipe Pampolini, Christopher B. Good
}

The authors are Saket S. Dasika, ASABE Member, Graduate Research Assistant, Department of Biosystems and Agricultural Engineering, University of Kentucky, Lexington, Kentucky; Michael P. Sama, ASABE Member, Assistant Professor, Department of Biosystems and Agricultural Engineering, University of Kentucky, Lexington, Kentucky; L. Felipe Pampolini, ASABE Member, Graduate Research Assistant, Department of Biosystems and Agricultural Engineering, University of Kentucky, Lexington, Kentucky; and Christopher B. Good, ASABE Member, Graduate Research Assistant, Department of Biosystems and Agricultural Engineering, University of Kentucky, Lexington, Kentucky; Corresponding author: Michael P. Sama, Department of Biosystems and Agricultural Engineering, 119 C.E. Barnhart Bldg. Lexington, KY 40546-0276; phone: 859-218-4325; e-mail: michael.sama@uky.edu.

\section{Abstract.}

The objective of this study was to determine the effect of sensor velocity and target height above ground level on height measurement error when using a multi-channel LiDAR sensor. A linear motion system was developed to precisely control the dynamics of the LiDAR sensor in effort to remove uncertainty in the LiDAR position/velocity while under motion. The linear motion system allowed the LiDAR to translate forward and backward in one direction parallel to the ground. A user control interface was developed to operate the system under different velocity profiles and to log LiDAR data synchronous to the motion of the system. The linear motion system performance was validated with a tracking total station and the results showed the position and velocity control error were negligible as compared to the LiDAR accuracy. The LiDAR was then validated using twenty-five test targets at varying heights above ground level $(0.1,0.3,0.5,0.6$, and $0.8 \mathrm{~m})$ with five different velocity profiles $(0.1,0.5,1.0,1.5$, and $2.2 \mathrm{~m} / \mathrm{s})$ and six replications to determine the effect of sensor velocity and target height on measurement error. Targets were painted white on one side and black on the other to determine the effect of relative intensity in LiDAR height measurement error. Generalized linear mixed models were fitted with the measurement error and the standard deviation in measurement error as the responses. Sensor velocity, target height, and their interaction were considered as fixed effects to determine if there were significant differences in average error and standard deviation of error for different sensor velocities and target heights. The results indicated that the velocity of the LiDAR was a significant factor affecting the average error and standard deviation of error in height measurements. However, higher velocities tended to only result in slightly larger average errors. A three-fold increase in the standard deviation was observed when increasing velocity from 0.1 to $2.2 \mathrm{~m} / \mathrm{s}$. Height of the target was either a weakly significant or insignificant factor in average error and a weakly significant factor affecting the standard deviation of the LiDAR measurements, representing mixed results. Average 
error and standard deviation were less than $10 \mathrm{~mm}$ and $30 \mathrm{~mm}$, respectively, for all replications. Relative intensities of the LiDAR measurements were $88.2 \%$ and $5.4 \%$ for white and black targets, respectively, and the different target colors exhibited a $4.7 \mathrm{~mm}$ shift in average estimated height error. These uncertainties may not be substantial for agricultural applications, where other sources of error, such as moving crop canopies or error in resolving position of the sensor are more likely to dominate overall measurement error.

\section{Keywords.}

LiDAR, Validation, Remote Sensing, Measurement Error, Precision Agriculture

\section{INTRODUCTION}

The use of unmanned aircraft systems (UAS), or drones, to estimate a crop's physical and biological properties has increased due to improvements in accuracy and efficiency (Malveaux et al., 2014). Crop physical properties, such as canopy height, canopy volume, and leaf area index (LAI) are useful for estimating fertilizer requirements (Stamatiadis et al., 2010), providing indication of health and potential yield (Colaço et al., 2017; Cui et al., 2010), modeling evapotranspiration, photosynthesis, and crop yield (Bonan, 1993), and understanding interactions between plants and solar radiation, water, and nutrients (Nie et al., 2016). UAS-based remote sensing typically have higher spatial and temporal resolutions than satellite and conventional aerial imagery (Zhang and Kovacs, 2012), which makes UAS-based remote sensing particularly suitable at the individual plant level.

There are multiple techniques used in capturing small-scale 3D information of the environment. Commonly used methods include laser, radar, and ultrasonic ranging sensors (Dworak et al., 2011). Laser, radar, and ultrasonic sensors are all active remote sensing techniques, which use time-of-flight (TOF), interferometry, or triangulation techniques to map the environment (Dworak et al., 2011; Vázquez-Arellano et al., 2016). In contrast, passive remote sensing techniques typically use image processing methods and are less accurate than active remote sensing techniques due to sunlight and environment issues (Kelly and Di Tommaso, 2015; Pittman et al., 2015; Sun et al., 2018). Ultrasonic sensors are not particularly suitable for crop remote sensing due to high attenuation, divergence, sensitivity to wind, and limited range. High-resolution radar sensors are expensive and typically exhibit a time delay for data acquisition, while low-cost radar sensors do not have the resolution required for remote sensing of crop physical structure (Dworak et al., 2011). High-resolution LiDAR, as compared to other ranging sensors, has higher spatial and temporal precision, and can map the environment more accurately (Lefsky et al., 2002).

LiDAR performance is robust in a wide range of environmental conditions making it suitable for agricultural use (Lin, 2015). Multiple studies have shown the utility of LiDAR for mapping crop or tree physical properties (Arnó et al., 2013; 
Estornell et al., 2011; Kelly and Di Tommaso, 2015; Mathanker et al., 2014; Weiss and Biber, 2011; Zhang and Grift, 2012). These studies used ground-based or conventional aircraft sensor deployments. Ground-based deployments are well suited to real-time sensing where high-resolution LiDAR data are used in feedback control systems to navigate or interact with objects. Conventional aircraft deployments typically produce lower spatial resolution data but can cover substantially larger areas. UAS presents a new opportunity to efficiently collect 3D measurements at both high spatial resolutions and over large areas. However, there are current limitations of small UAS in terms of payload capacity and range (Guo et al., 2012; Zhang and Kovacs, 2012). A common assumption is that the drone is moving at a constant velocity (Sun et al., 2018) or the drone's GPS/IMU are accurate enough to predict position and orientation. In all these cases, there is some uncertainty in the velocity and pose of the drone that contributes to LiDAR measurement error. Prior to implementing drone-based LiDAR measurements for generating 3D models of large agricultural fields, the accuracy and precision of the LiDAR sensor should be evaluated in a more controlled manner to reduce external effects on the LiDAR measurement error.

As the velocity of a drone increases the point density decreases for a constant LiDAR sampling rate. Lower point density reduces the spatial measurement resolution. One of the research questions this study seeks to understand is to how fast a LiDAR sensor can travel without having a significant deviation in the measured height of an object due to a decrease in point density. This study also investigates how the relative height of targets within a given field-of-view (FOV) affect point density for a given velocity as a result of the geometry between the LiDAR and the targets. A predefined test target can be used to quantify LiDAR performance and perform statistical tests on the LIDAR data to show if significant differences in height measurements with different sensor velocities and target heights exist. Zhang and Grift (2012) conducted similar research on estimating the crop height and they found an increase in average error of the stem height with an increase in the velocity of LiDAR due to reduction in point density. Sanz-Cortiella et al. (2011) also conducted an experiment where a 3D LiDAR was translated on a multi-purpose test rail where the LiDAR was driven at 3 speeds and 2 angular resolutions and found a linear relationship between number of impacts and leaf area measurements. In the two previously mentioned studies, the target was a living object that was potentially subject to movement, which could have influenced error measurements between treatments. This study expands on previous work by performing tests on a well-defined static target to improve the ability to detect significant differences in height measurement error based upon LiDAR velocity, target height, and relative intensity of the LiDAR signal for a multi-channel LiDAR sensor. Better understanding of height measurement error will be key to successfully deploying UAS-based LiDAR measurements for 3D remote sensing in agriculture.

\section{OBJECTIVES}

The overall objective of this study was to determine the effect of sensor velocity and target height above ground level on height measurement error when using a multi-channel LiDAR sensor. The specific objectives were as follows: 
1. Develop a linear motion system to constrain and control the dynamics of the LiDAR over a test target.

2. Develop software to log and process LiDAR data collected with the linear motion system.

3. Validate the LiDAR using test targets and determine the effect of target height, LiDAR velocity, and test target intensity on measurement error.

\section{Materials ANd Methods}

\section{TEST FIXTURE COMPONENTS}

A linear motion system was built to control the dynamics of a multi-channel 3D LiDAR sensor. The linear motion system consisted of a carriage assembly (Figure 1), which translated along the linear rails via a force supplied by a timing belt. A 16-channel LiDAR (VLP-16, Velodyne LiDAR, San Jose, CA) was integrated onto the carriage assembly and interfaced to a PC for data acquisition through a flexible cable carrier (Series 20, Igus Inc., East Providence, RI). The LiDAR sensor had a measurement range of 1 to $100 \mathrm{~m}$ and broadcasted 754 User Datagram Protocol (UDP) data packets per second over an ethernet connection. Each UDP data packet was organized in 12 data blocks consisting of rotation angles (azimuth and elevation), time of flight distances, calibrated reflectivity measurements and a local timestamp associated with every measurement. The LiDAR sensor was capable of reporting distances in two measurement modes. The first, referred to as single return mode, reported a single measurement corresponding to the strongest signal. The second, referred to as dual return mode, reported the strongest and last signals detected for each laser firing. Rotational speeds between 300 and 1200 RPM $(5-20 \mathrm{~Hz})$ were available in $60 \mathrm{RPM}$ increments. For this study, the LiDAR was configured to report the strongest returns (generally the closer object) and to rotate at $600 \mathrm{RPM}(10 \mathrm{~Hz})$, which were the default settings. The measurement rate was 289344 samples per second and was not adjustable. Increasing or decreasing the rotational speed of the LiDAR sensor had the effect of redistributing the location of measurements but did not change the number of measurements per unit area. Therefore, testing at different rotational speeds was deemed unnecessary when scanning uniformly shaped targets.

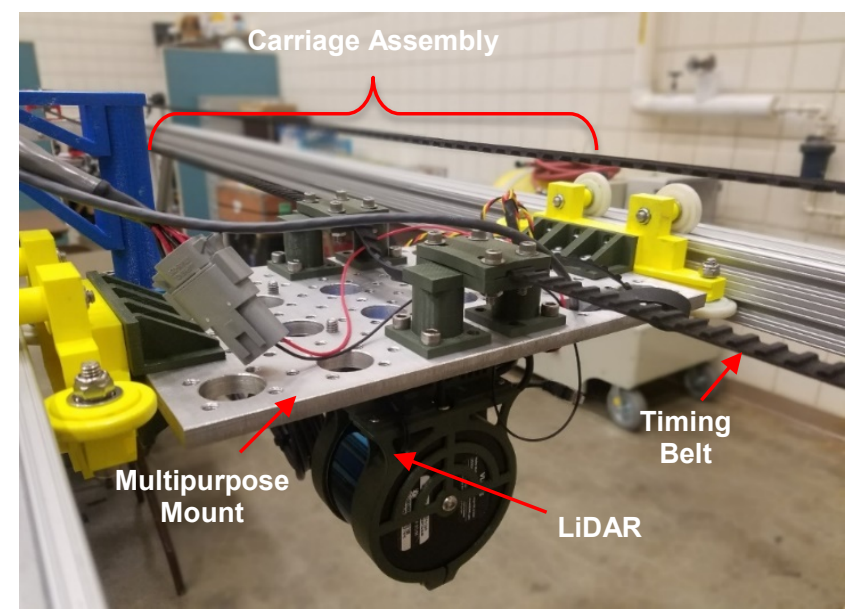

Figure 1: Linear motion system carriage assembly with the LiDAR translating on the linear rails via a force supplied by a timing belt. 
The linear motion system was mounted onto a frame assembly to set the height of the LiDAR at approximately $2 \mathrm{~m}$ above the ground, allowing targets up to $1 \mathrm{~m}$ tall to be scanned. The top assembly and frame assembly were connected using a sliding joint (Figure $2 b$ ) for simple dismount during transportation.

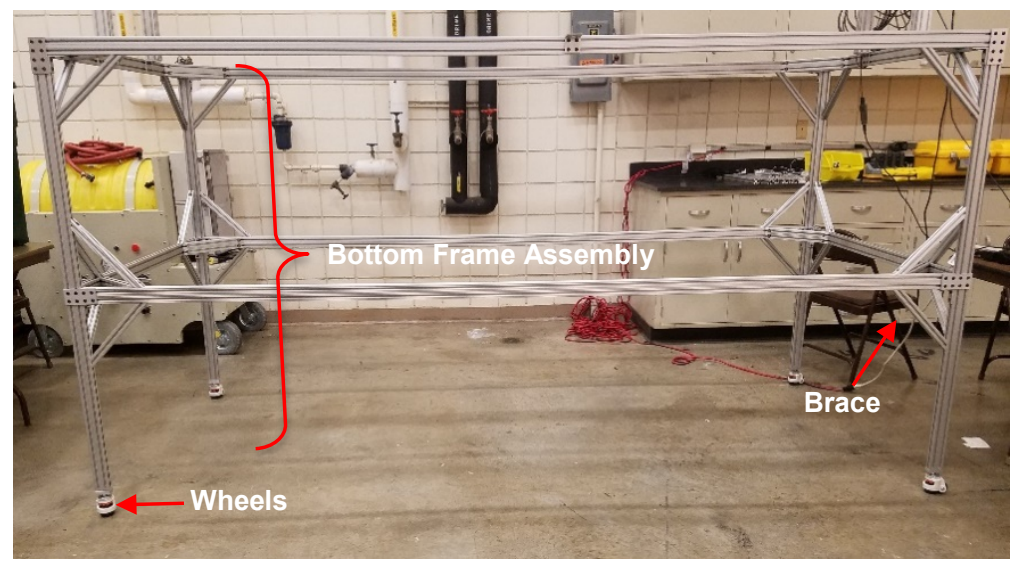

(a)

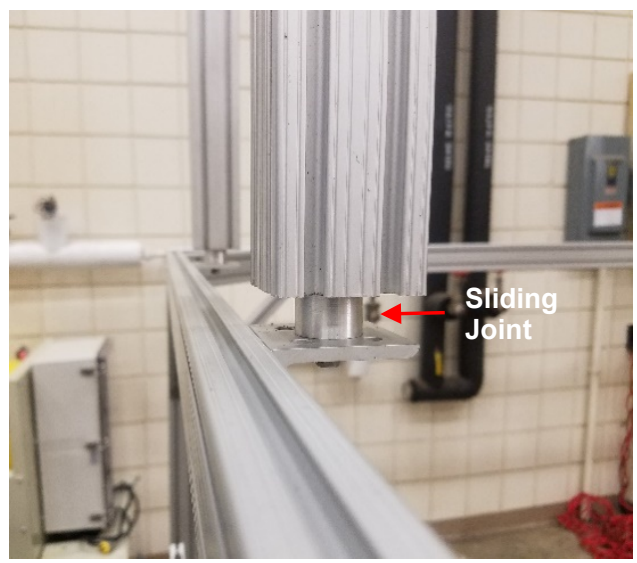

(b)

Figure 2: (a) Frame assembly with the major components identified and (b) sliding joint connecting the top and bottom frame assemblies. The frame assembly was used to position the LiDAR sensor at the minimum height above ground level needed to scan $1 \mathrm{~m}$ targets.

\section{Motion CONTROL SYSTEM}

The maximum acceleration of the system was initially set at $5 \mathrm{~m} / \mathrm{s}^{2}$ to assist with motion component specification. The mass of the carriage and LiDAR assembly was approximately $3 \mathrm{~kg}$. A $3.06 \mathrm{~N} \mathrm{~m}$ stepper motor (STP-MTRH-34066D, AutomationDirect, Cumming, GA) was coupled with a $2.73 \mathrm{~cm}$ pitch radius timing pulley to provide a force for translating the carriage assembly. The required motor torque based upon the carriage mass and pitch radius was $0.41 \mathrm{~N} \mathrm{~m}$, resulting in a factor of safety of approximately 7.5. This allowed for higher accelerations to be achieved, but more importantly, sufficient torque was available to ensure that the stepper motor would not miss a step under normal operating conditions - a necessary criteria to ensure accurate position/velocity control.

All motion control electronics were housed in a plastic enclosure box (Figure 3) and mounted to the side of the top frame assembly. Electronic components included a 70 VDC power supply (STP-PWR-7005, AutomationDirect), which supplied power to a regeneration clamp (STP-DVRA-RC-050, AutomationDirect) to protect the system from back-EMF produced by the motor during high decelerations. The regeneration clamp powered a bi-polar stepper motor controller (STP-DVR80100 , AutomationDirect), which drove the stepper motor at the desired velocity profile based upon serial data inputs. Additional power supplies (5/12/24 V) were integrated to provide power to the LiDAR and for future instrumentation. 


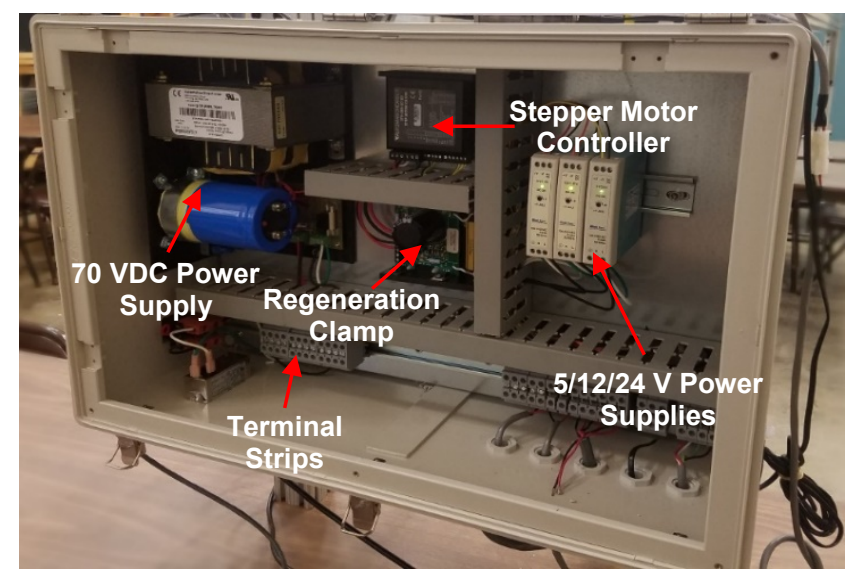

Figure 3: Motion control system electronics enclosure box used to drive the stepper motor and supply power to the LiDAR sensor.

\section{Safety Precautions}

The linear motion system (Figure 4) was equipped with a kill switch to disengage power in case of emergency. Limit switches (SZL-VL-A, Honeywell International Inc., Morris Plains, NJ) were also placed on either end of the linear rail to disengage the stepper motor power whenever the carriage assembly tripped the limit switch - thereby protecting the linear motion system from potential mechanical failure due to improper operation or software malfunction. The limit switch closest to the plastic enclosure box was also used to index the start position of the linear motion system. 


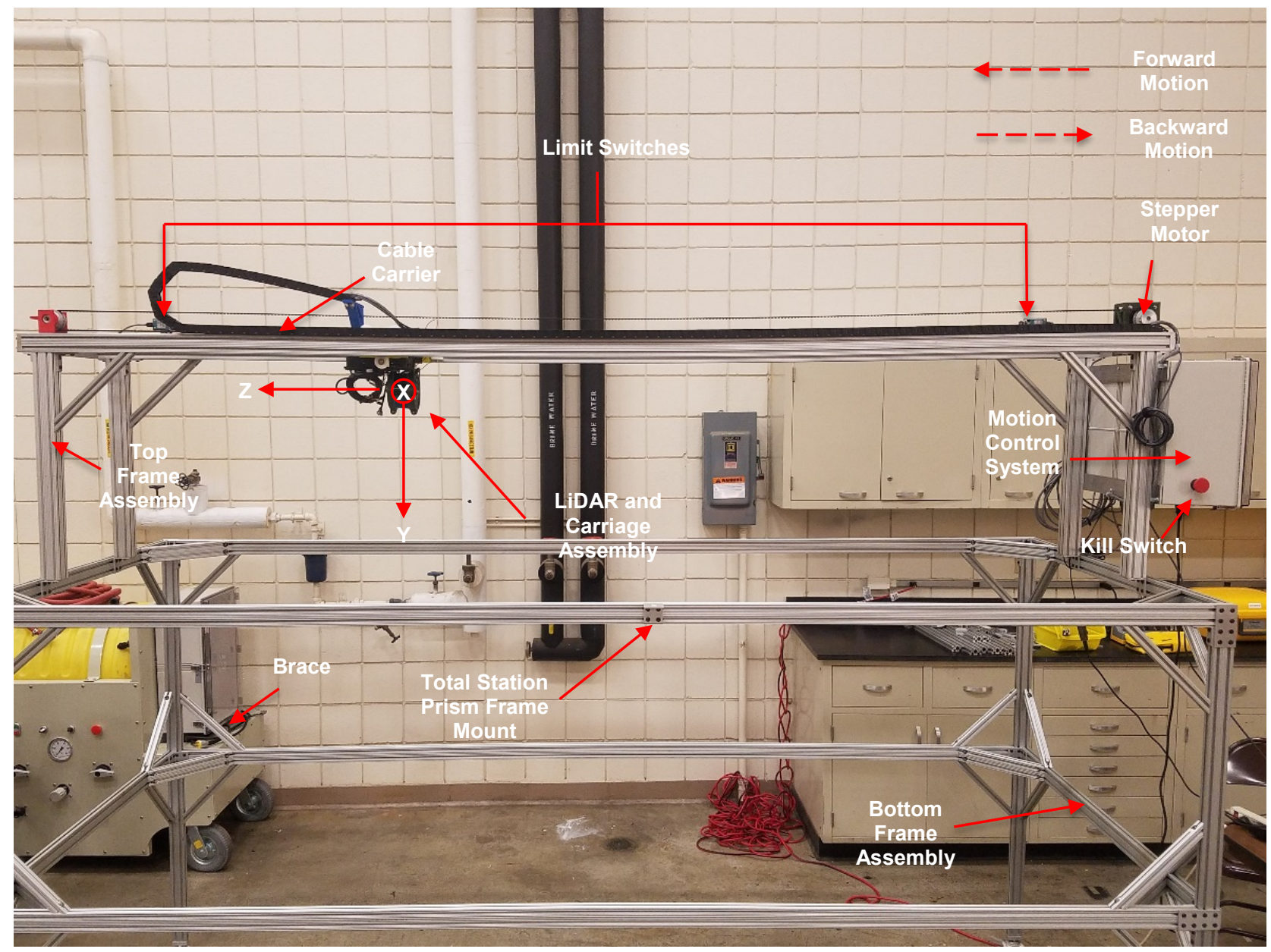

Figure 4: Complete linear motion system assembly designed to translate a LiDAR sensor at constant velocity over a 1x1x1 m test volume.

\section{USER INTERFACE}

A PC-based user interface was developed to control the velocity profile of the linear motion system and to record LiDAR data. The user interface shown in Figure 5 was developed in Python (2.7, Python Software Foundation, Beaverton, OR) using the Tkinter graphic user interface (GUI) toolkit. Tkinter functions were imported in Python and a class was defined for software configuration. Combo boxes were used to provide preset values controlling acceleration, velocity, deceleration, and total displacement. Preset values could be overwritten by entering in custom values into any combo box, but were software limited in terms of their maximum values. Four buttons were implemented to provide the following capability:

1. Connect - opens the serial port and send the necessary commands through the serial port to initialize the stepper motor controller

2. Disconnect - closes the serial port, releasing the stepper motor controller

3. Run - simultaneously sends motion commands to the stepper motor controller to run the carriage assembly in the desired velocity profile and connects to the UDP port to log the data from the LiDAR 
4. Start Position - sends a series of commands to the stepper motor controller to ensure the system starts at the same place every time by slowly moving the carriage assembly in the backward direction until it strikes the start position limit switch.

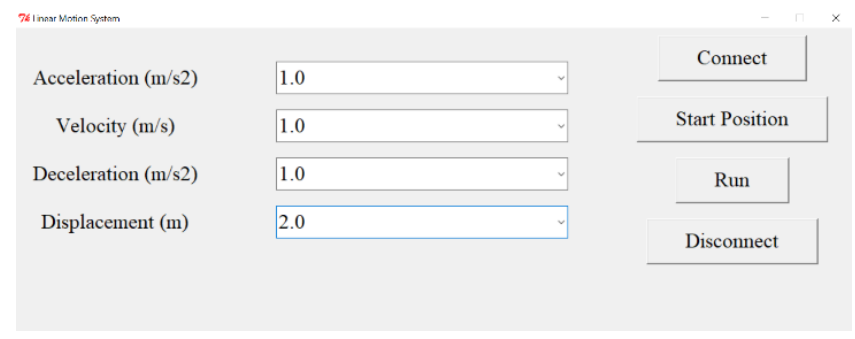

Figure 5: User control interface for selecting different velocity profiles. Drop down combo boxes allowed the user to select pre-defined or custom acceleration, steady-state velocity, deceleration, and displacement settings. Settings were transmitted to the stepper motor controller via a series of RS-232 strings upon clicking the run button.

After connecting to the serial port and clicking "Start Position", the carriage assembly translated backward towards the start position limit switch until the start limit switch was pressed, at which point the carriage immediately stopped and the linear motion system location was set to the machine zero. The carriage assembly was then moved $0.1 \mathrm{~m}$ forward and a local zero was set. The offset between the machine and local zero locations provided a "soft limit" to ensure that the mechanical limit switches would not be reached under normal operating conditions.

The motion control and data logging flow diagram shown in Figure 6 illustrates the process of simultaneously sending commands to the stepper motor controller, starting the LiDAR data logging thread, and starting the carriage position measurement thread when clicking the "Run" button. The LiDAR data logging thread consisted of a connection to a UDP port with an IP address and port number specified configured to match the LiDAR data stream. A comma-separated values (CSV) file was created each time the "Run" button was pressed with the current date and time as the file name. The LiDAR data blocks were encoded into hexadecimal format and parsed into the CSV file. The carriage position detection thread continuously polled the stepper motor controller nominally at $50 \mathrm{~Hz}$ to determine the position of the carriage as it translated forward and backward. When the carriage assembly returned to the original start position, an event was raised to break the LiDAR data logging thread, thereby stopping data logging and closing the CSV file. 


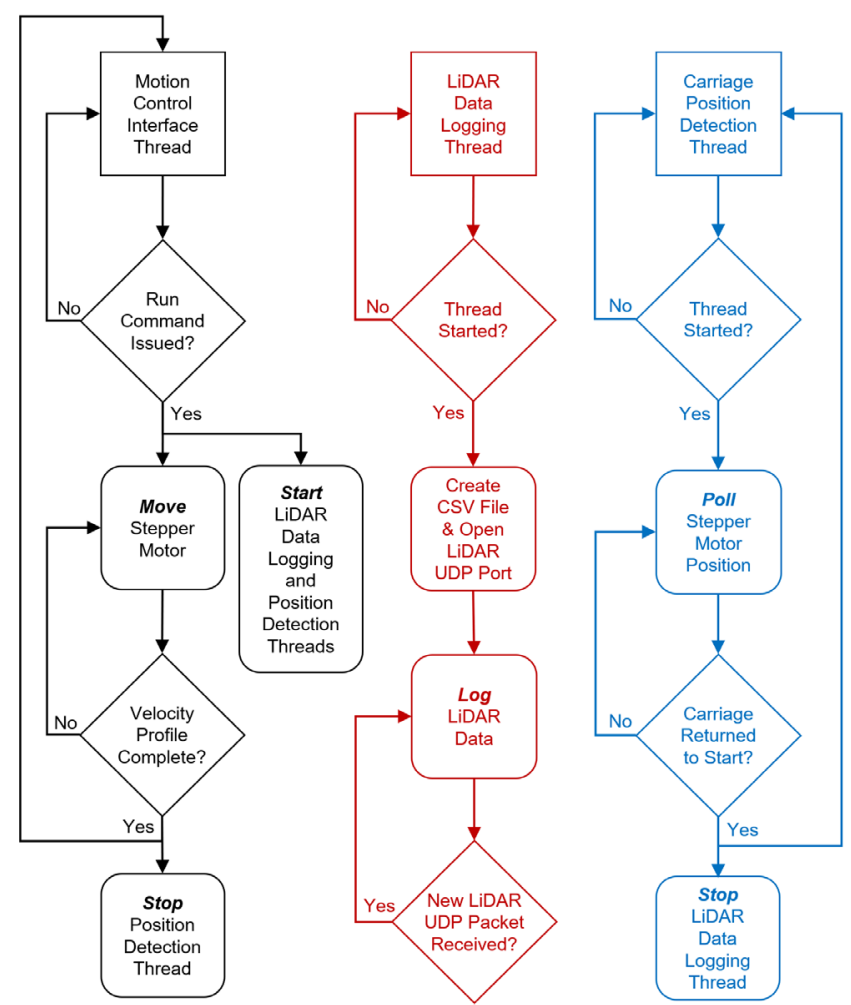

Figure 6: Motion control and data logging flow diagram illustrating the order of steps followed to log LiDAR data. Motion control (black), LiDAR data logging (red), and carriage position detection (blue) run on separate processing threads to minimize latency within each thread.

\section{LINEAR MOTION SYSTEM VALIDATION}

The linear motion system performance was validated using a robotic total station (S5, Trimble Inc., Sunnyvale, CA) (Figure 7). The total station automatically tracked a prism (MT1000, Trimble Inc.) and was used for three different validation experiments:

1. Frame movement validation - the prism was fixed to a horizontal rail on the bottom frame assembly to detect motion in the linear test fixture frame due to acceleration/deceleration of the carriage.

2. Position validation - the prism was fixed to the carriage assembly to determine displacement accuracy of the carriage assembly when moving between locations.

3. Steady-state velocity validation - the prism was fixed to the carriage assembly to determine velocity accuracy of the carriage assembly under steady-state velocity.

Uncertainty validation measurements were taken at 7 different velocity profiles (distance $=2.0 \mathrm{~m}$, acceleration/ deceleration $=1$ to $5 \mathrm{~m} / \mathrm{s}^{2}$, velocity $=1$ to $2 \mathrm{~m} / \mathrm{s}$ ) with 2 replications. Position control validation measurements were taken at 4 different distances $(0.5,1.0,1.5$, and $2.0 \mathrm{~m})$ with 3 replications. Steady-state velocity validation measurements were taken at 3 different velocities $(0.1,0.5$, and $1.0 \mathrm{~m} / \mathrm{s})$ with 3 replications for each velocity. The measurements were logged at 
$2.5 \mathrm{~Hz}$ through a serial port on the total station controller and saved in a text file.

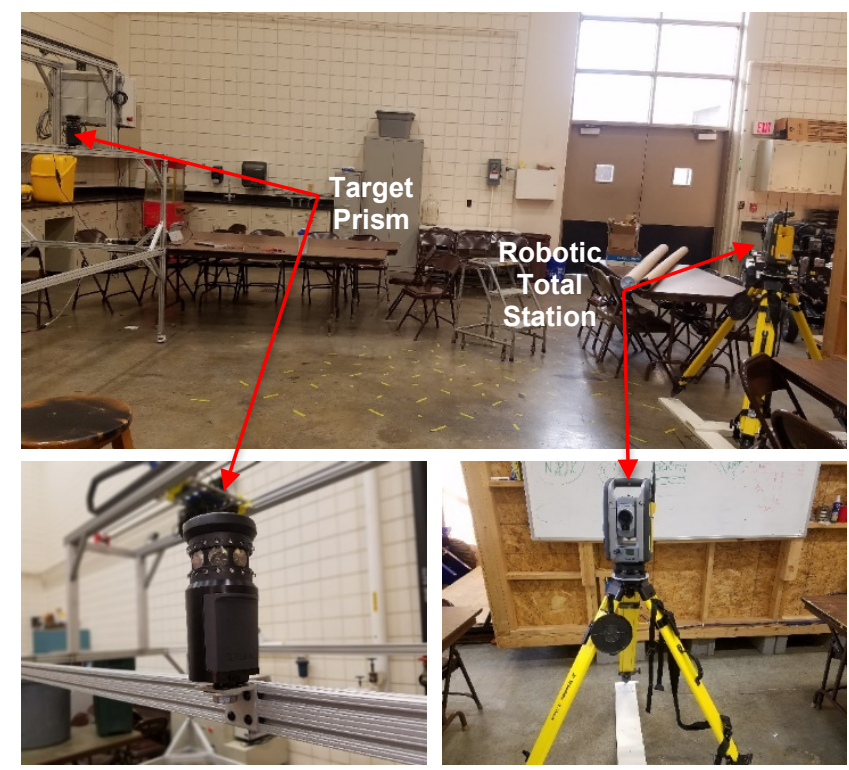

Figure 7: Validation of the linear motion system performance using a robotic total station and target prism. The robotic total station automatically tracked and reported the position of the target prism on a $0.4 \mathrm{~s}$ interval.

\section{LIDAR DATA PROCESSING AND ANALYSIS}

The work flow of the LiDAR data processing is shown in Figure 8. Initially, the raw LiDAR data were fed into a MATLAB script (R2016a, MathWorks, Natick, MA). A 1x16 cell structure array titled distance was initialized with each cell corresponding to a particular channel and consisting of a 3-dimensional matrix with dimensions Nx12x2 (number of packets by twelve data blocks per packet by two values per each channel per each data block). The hexadecimal values in the data packets were converted into decimal format, which gives the azimuth angle values, time of flight distance values and calibrated reflectivity values. The elevation angles were fixed for a given channel given the linear translation of the LiDAR sensor. The VLP-16 sensor had 16 pairs of infra-red laser diode and detectors equally spaced between \pm 15 degrees from the rotational plane. Data corresponding to the appropriate channel (values 0-15) were stored in the each of the cells in the distance cell structure array. The distances, azimuth angles and elevation angles mapped the environment in spherical coordinates, and were converted into Cartesian coordinates (x, y, z) shown in Figure 4 using the following formulae:

$$
\begin{aligned}
& X_{n}=r_{n} \cos \left(\omega_{n}\right) \sin \left(\alpha_{n}\right) \\
& Y_{n}=r_{n} \cos \left(\omega_{n}\right) \cos \left(\alpha_{n}\right) \\
& Z_{n}=r_{n} \sin \left(\omega_{n}\right)
\end{aligned}
$$

where

$$
\mathrm{r}_{\mathrm{n}}=\text { distance of sample number ' } \mathrm{n} \text { ' }(\mathrm{mm})
$$


$\omega_{\mathrm{n}}=$ elevation angle of sample number ' $\mathrm{n}$ ' $\left(^{\circ}\right)$

$\alpha_{\mathrm{n}}=$ azimuth angle of sample number ' $\mathrm{n}$ ' $\left({ }^{\circ}\right)$

$\mathrm{n}=$ sample number

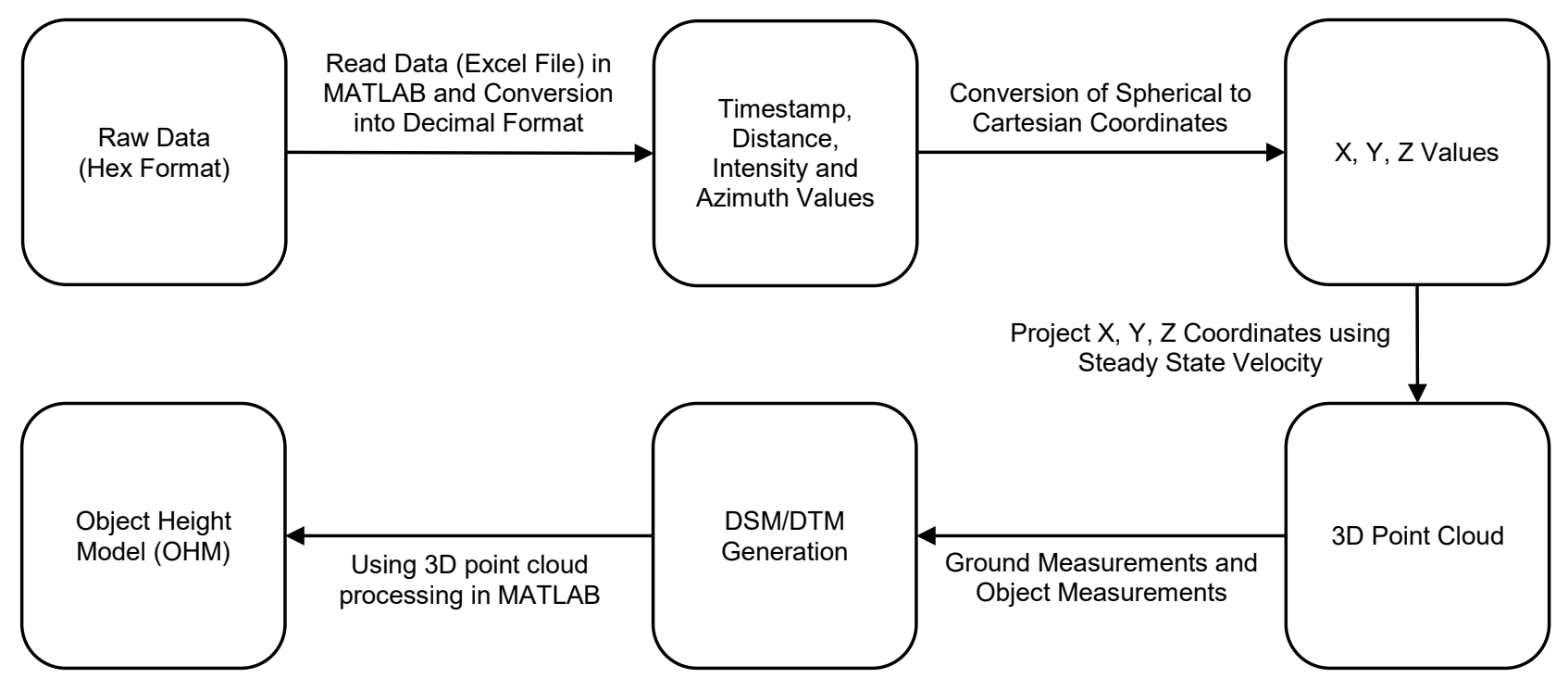

Figure 8: Data processing flow diagram showing the order of steps performed to acquire the object height model. Raw data provided by the LiDAR sensor are imported into MATLAB to extract the 3D point cloud representing the target height above ground level.

Since data logging was synchronized with the motion of the system, the first and last timestamps represented the beginning and end of the motion profile, respectively. The LiDAR position was determined using the timestamp and basic kinematic equations. Only data collected during the steady-state portion of each test were used in analysis. The resulting data were split into two datasets, one for forward motion and the other for backward motion. Cartesian coordinates obtained were projected into 3D space in the z-axis (direction of travel, Figure 4) using the steady state velocity by one of the two following formulae:

$$
\begin{aligned}
& Z_{n t}=r_{n} \sin \left(\omega_{n}\right)+v\left(t-t_{0}\right) \\
& Z_{n t}=r_{n} \sin \left(\omega_{n}\right)-v\left(t-t_{0}\right)
\end{aligned}
$$

Where

$$
\begin{aligned}
& Z_{n t}=z \text {-coordinate of sample number ' } n \text { ' at time ' } t \text { ' }(\mathrm{mm}) \\
& r_{n}=\text { distance of sample number ' } n \text { ' }(\mathrm{mm}) \\
& \omega_{n}=\text { elevation angle of sample number ' } n \text { ' }\left({ }^{\circ}\right) \\
& v=\text { steady state velocity }(\mathrm{m} / \mathrm{s}) \\
& \mathrm{t}=\text { instantaneous timestamp }(\mathrm{s})
\end{aligned}
$$




$$
\mathrm{t}_{0}=\text { initial timestamp (s) }
$$

Equation (4) was used to compute the z-coordinate in forward motion and equation (5) was used to compute the zcoordinate in backward motion. Thus, the local 3D point cloud relative to the linear motion system was obtained after projecting the LiDAR data into 3D space.

A common technique to quantify the physical height of an object relative to the ground plane was used. Referred to as an object height model (OHM), the OHM was computed from the digital terrain model (DTM) and digital surface model (DSM) of the object. The DTM represented ground measurements whereas the DSM consisted of objects detected above ground level. The DTM was subtracted from the DSM to obtain the OHM, and the OHM was used to extract height measurements in a given region of interest.

\section{TEST TARGET EXPERIMENT}

The test target shown in Figure 9a was used to validate the LiDAR sensor when translating on the linear motion system at different velocities. The target consisted of 25 plates mounted to vertical tubes of 5 different heights pseudo-randomly arranged in the order as shown in Figure 9b, where no height was repeated in a single row or column. The tubes were bolted onto a $1 \mathrm{~m}$ x $1 \mathrm{~m}$ x $1.9 \mathrm{~cm}$ medium-density fiberboard (MDF) base using countersunk machine screws. A magnet embedded in a 3D printed plastic mount was pressed into the top of each tube. Sheet metal steel plates $(0.2 \mathrm{~m} \times 0.2 \mathrm{~m} \times 3 \mathrm{~mm})$ were centered on each magnetic mount. The plates were painted flat black on one side and flat white on reverse side to provide two relative intensity values when recording LiDAR data.

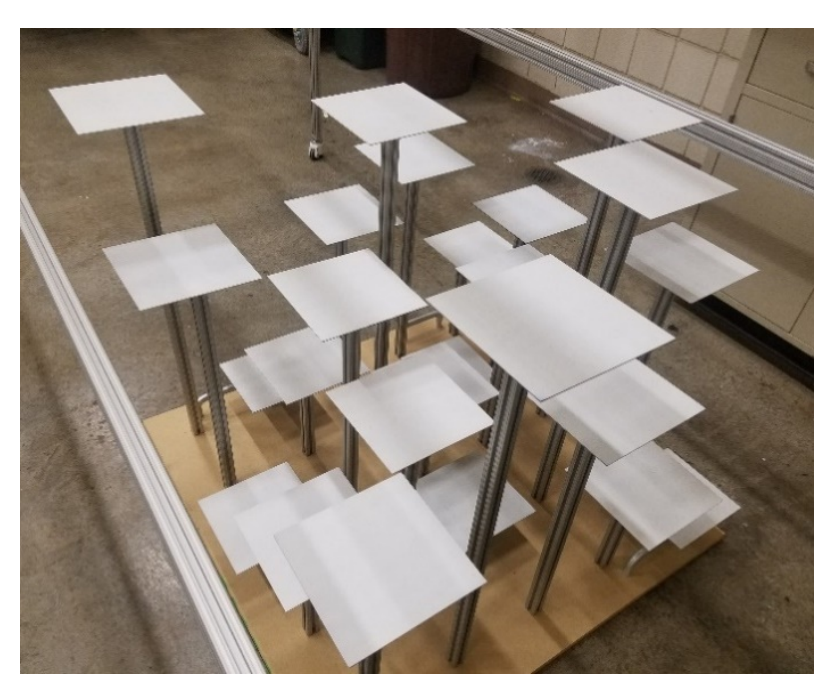

(a)

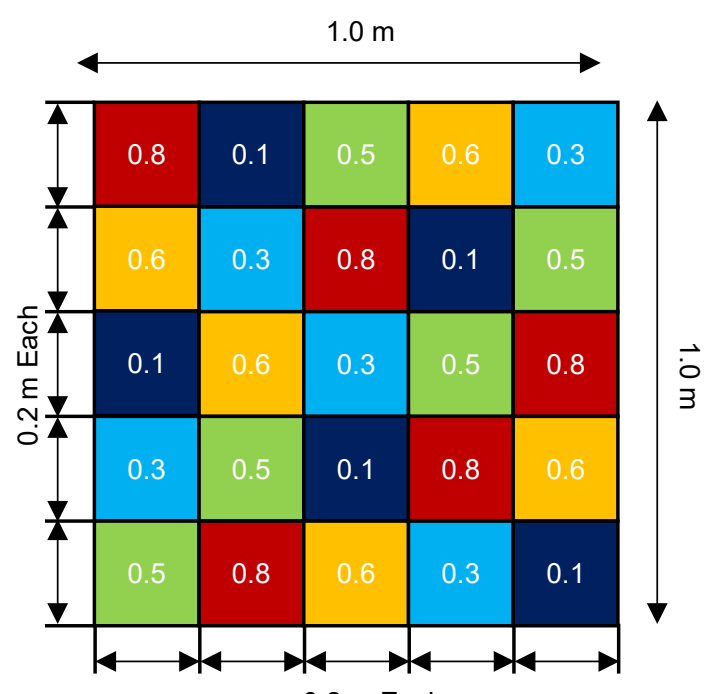

$0.2 \mathrm{~m}$ Each

(b)

Figure 9: (a) Orientation and placement of the test target underneath the LiDAR; (b) Physical layout showing the arrangement of heights of individual test targets.

The test target was located in the middle of the frame and the sides of the MDF base were aligned parallel to $\mathrm{x}$ - and z- 
axes. The LiDAR sensor translated above and across the LiDAR test target. The LiDAR sensor scanned the test target while translating forward and backward for a single velocity profile. LiDAR data were collected in five different velocity profiles and replicated three times. Each replication was split into two different scans, one for forward motion and one for backward motion $(5 \times 3 \times 2)$. The entire experiment was repeated for the white and black side of the target plates. The ground (i.e., floor) measurements were taken prior to target measurements at the lowest velocity profile. Table 1 shows the order in which data were collected for each target color. Velocities within each replication were pre-determined randomly and the same order was applied when scanning white and black targets.

Table 1: LiDAR data collection procedure with the order of velocities. The order of velocities within a replication were randomized.

\begin{tabular}{cc}
\hline Velocity $(\mathbf{m} / \mathbf{s})$ & $\begin{array}{c}\text { Replication } \\
\text { Number }\end{array}$ \\
\hline 1.0 & 1 \\
0.1 & 1 \\
0.5 & 1 \\
1.5 & 1 \\
2.2 & 1 \\
0.1 & 2 \\
1.0 & 2 \\
2.2 & 2 \\
0.5 & 2 \\
1.5 & 2 \\
2.2 & 3 \\
1.5 & 3 \\
1.0 & 3 \\
0.1 & 3 \\
0.5 & 3 \\
\hline
\end{tabular}

\section{Point Cloud Processing of the Test Target}

The DTM was obtained immediately before scanning the white and black targets. The average height of the ground was determined using a region of interest (ROI) with a dimension of $\pm 0.1 \mathrm{~m}$ in the $y$-axis at the expected ground level to filter out extraneous points. The resulting ROI was split into 100 x 100 blocks $(0.01 \times 0.01 \mathrm{~m})$ on the xz-plane. For each block, the points lying inside were found and the average of the points inside each block was computed. The average of the 100 blocks was then found and termed the "average height" of the ground. The average height was used for this experiment as a constant height DTM since the ground was relatively smooth. However, future experiments could use the $100 \mathrm{x} 100 \mathrm{block}$ matrix to represent a more variable ground surface.

Two MATLAB scripts were written for processing the forward and backward scans to obtain height measurements of the targets. Figure 10a is an example of the raw point cloud data collected when the LiDAR sensor was travelling at $1.0 \mathrm{~m} / \mathrm{s}$ in the forward direction. Figure $10 \mathrm{~b}$ shows the targets at $0.8 \mathrm{~m}$ extracted from the point cloud in Figure $10 \mathrm{a}$ using a $\pm 0.1 \mathrm{~m}$ ROI along the $y$-axis centered at a height of $0.8 \mathrm{~m}$ above the ground level. 


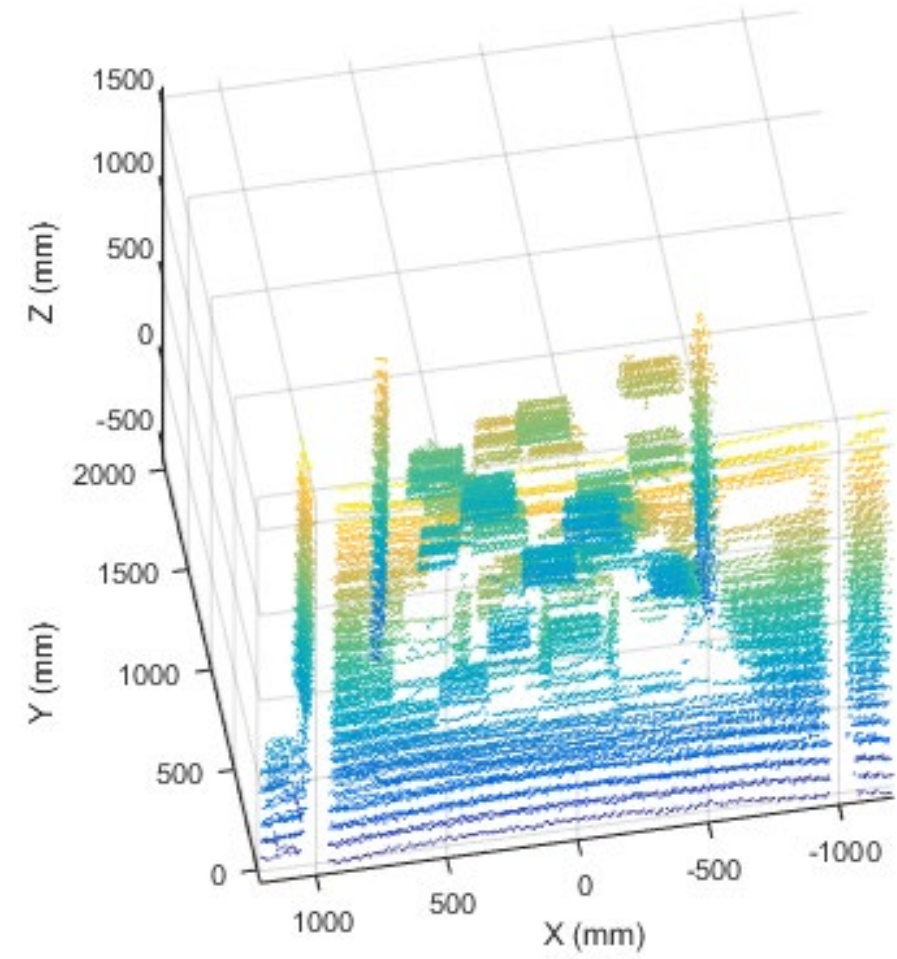

(a)

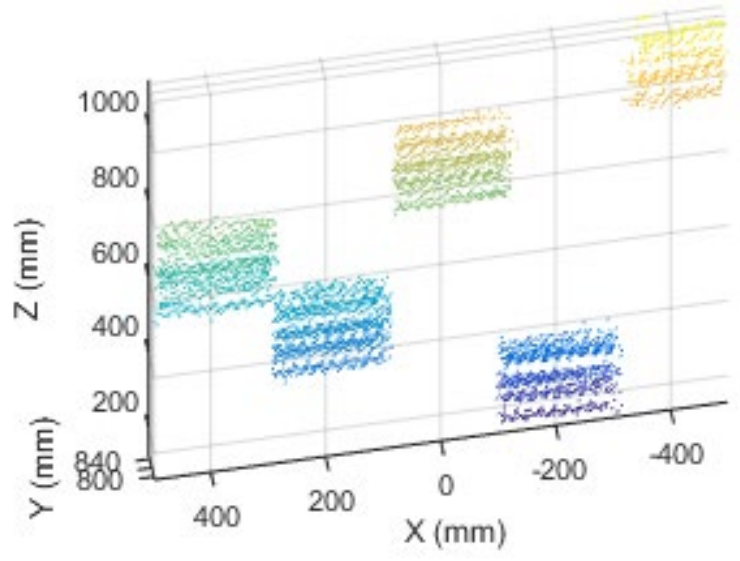

(b)

Figure 10: Example LiDAR point cloud data of (a) the entire test target area and (b) points associated with $0.8 \mathrm{~m}$ height targets. The LiDAR sensor velocity was set to $1.0 \mathrm{~m} / \mathrm{s}$ and points associated with individual targets were isolated using a ROI filter.

Twenty-five different ROI's were defined for each of the 25 targets to extract points associated with each target. For a three-dimensional ROI corresponding to a particular target, the y-axis range was a total of $0.2 \mathrm{~m}( \pm 0.1 \mathrm{~m}$ from the actual target height based upon the ground location) for the $0.1 \mathrm{~m}, 0.3 \mathrm{~m}$ and $0.8 \mathrm{~m}$ height targets, and $0.1 \mathrm{~m}( \pm 0.05 \mathrm{~m}$ from the actual target height based upon the ground location) for the $0.5 \mathrm{~m}$ and $0.6 \mathrm{~m}$ height targets. The decrease in the y-axis range for the $0.5 \mathrm{~m}$ and $0.6 \mathrm{~m}$ targets was to reduce the overlap of the corresponding ROIs due to the smaller separation distance between the height of these two targets. The ROI range of $\mathrm{x}$-axis and z-axis for each target was $\pm 0.1 \mathrm{~m}$ centered at the approximate center location of each target. This provided a large buffer around each ROI to ensure points from adjacent targets were not accidentally associated with a given target due to potential misalignment between the linear motion system and the test target.

The points lying inside each ROI were extracted and associated with the corresponding target. In addition to retaining the raw height measurements within a ROI for statistical analysis, other attributes computed from the points in each ROI included estimated average height, standard deviation in height, number of points on a particular target (point density), missing targets (targets where there were less than 10 points on them due to high speed or FOV obstruction due to adjacent targets), and average intensity. All processed data were organized into a single Excel file where each spreadsheet consisted of one replication with five different velocity profiles and twenty-five different targets of five different heights. 


\section{RESULTS AND DISCUSSION}

\section{LINEAR MOTION SYSTEM VALIDATION}

Data from the robotic total station showed no movement in the frame $(<1 \mathrm{~mm})$ when accelerating/decelerating the carriage up to $5 \mathrm{~m} / \mathrm{s}^{2}$. The absolute position error of the linear motion system as measured by the robotic total station was a function of distance travelled, resulting in 2 millimeters of error per meter travelled. Similarly, the absolute error in the velocity was approximately $2 \mathrm{~mm} / \mathrm{s}$ when traveling at $1 \mathrm{~m} / \mathrm{s}$. Both the error in position and velocity were an order of magnitude smaller than the specified measurement accuracy of the LiDAR sensor $( \pm 3 \mathrm{~cm})$ and were considered negligible when projecting LiDAR data from the sensor spherical coordinate system to a local Cartesian coordinate system. Position and velocity error were likely due to calibration error when indexing the robotic total station into the linear motion system local coordinate system. No backlash was detected when moving the carriage back and forth to the same position.

\section{LIDAR FIRMWARE VERSION}

Drift in the average distance to a stationary object was encountered when initially testing the LiDAR, which was in excess of $10 \mathrm{~cm}$ from the time the LiDAR was powered on until reaching a steady-state value after approximately 20 minutes. Drift was determined to be due to changes in the internal temperature of the LiDAR and was mitigated through a firmware update. The maximum variability in measurements to the ground surface were less than $0.5 \mathrm{~cm}$ when using the updated firmware, which was well within the accuracy specifications of the LiDAR. Figure 11 illustrates the distance to the ground surface measured by the LiDAR as a function of LiDAR temperature (internal sensor). Note that newer versions of the firmware were available but not used in this experiment due to the need to return the sensor to the manufacturer for update beyond version 3.0.24.1.

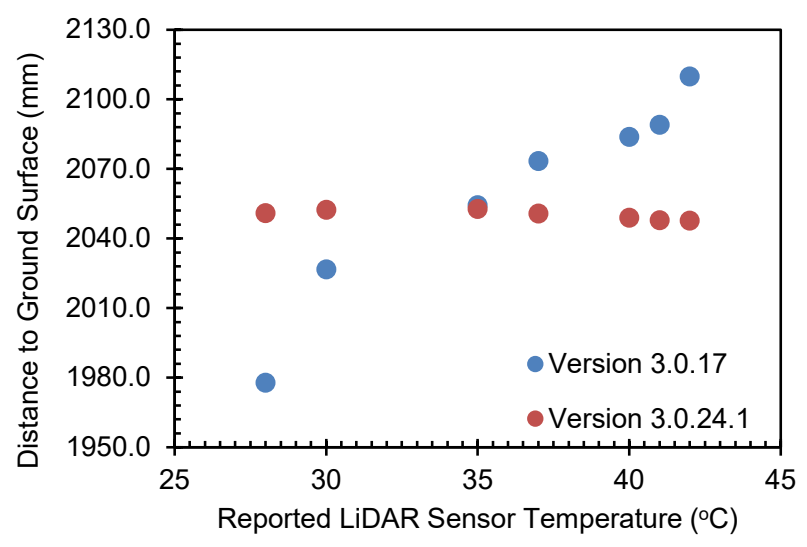

Figure 11: Temperature response of the LiDAR sensor as exhibited by measured distance the ground surface at varying LiDAR sensor temperatures. The newer firmware version mitigated the effect of temperature on distance measurements.

\section{TEST TARGET EXPERIMENT}

The purpose of this experiment was to study the accuracy and precision of a LiDAR sensor when measuring a predefined test target and assess its performance for different velocities and target heights. The estimated height of a single target from 
the LiDAR was calculated as the average height of all the raw data points within the boundary of the target. Target height error was calculated by subtracting the actual height from the estimated height. Figure 12 shows the height measurement error results as box and whisker plots for both height and velocity when measuring the white and black targets.

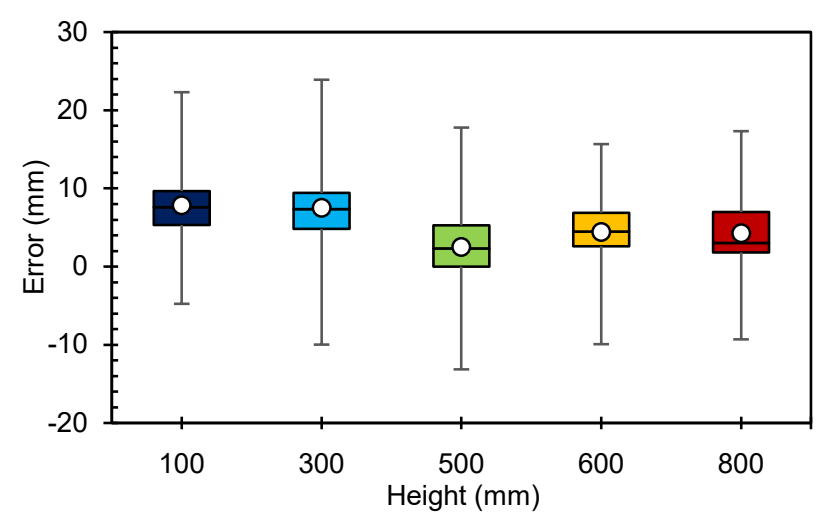

(a)

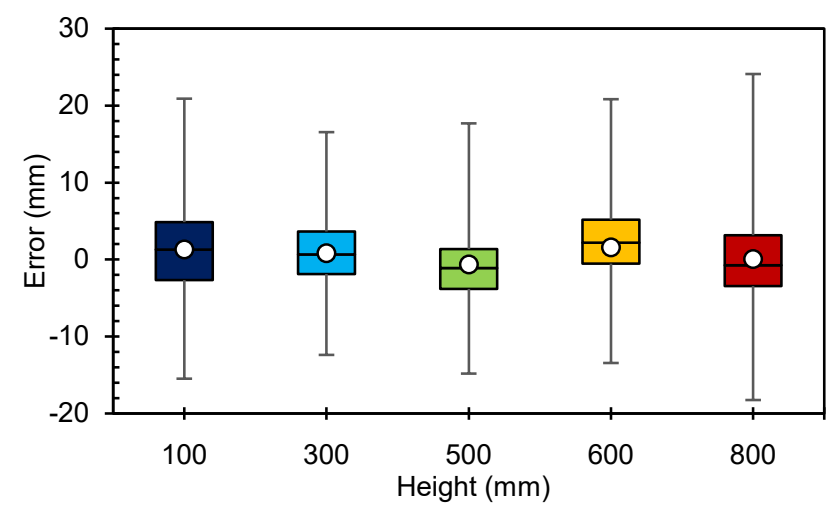

(c)

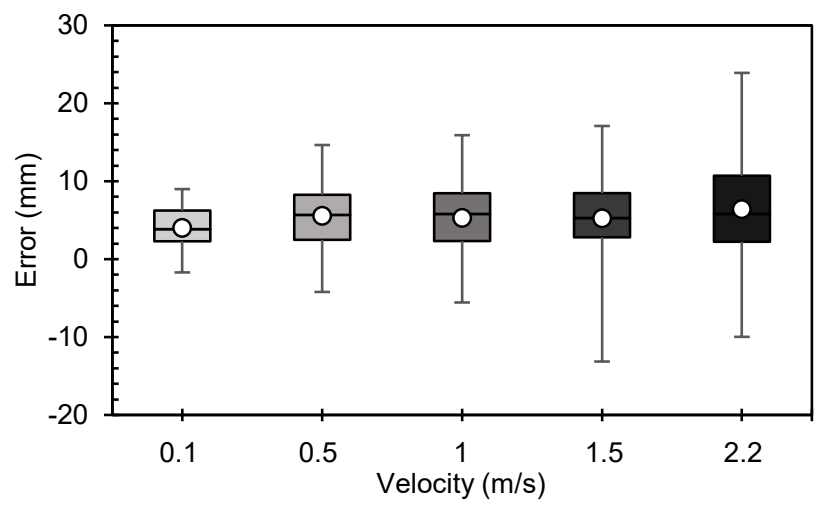

(b)

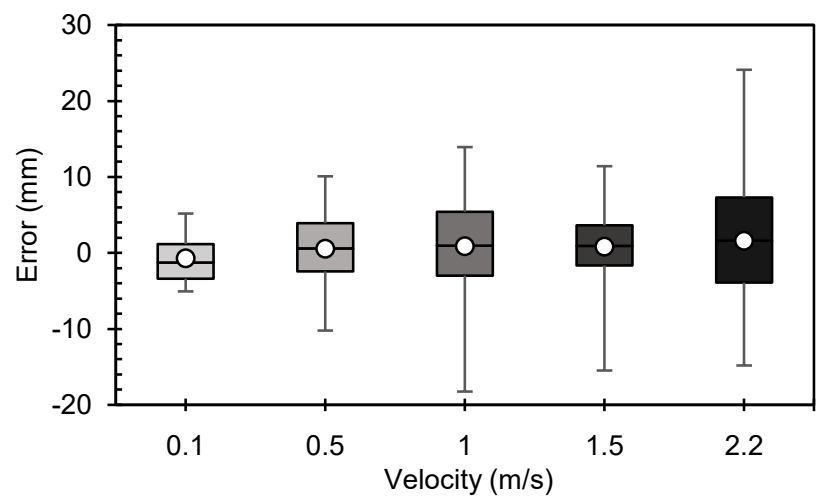

(d)

Figure 12: Box and whisker plots illustrating the distributions of estimated height measurement errors for: (a) actual height of white targets; (b) LiDAR sensor velocity when scanning white targets; (c) actual height of black targets and; (d) LiDAR sensor velocity when scanning black targets. Dots and midlines represent the mean and median values, respectively, across all replications of a given target height or velocity. Boxes show the $25 \%$ to $75 \%$ quartile values. Whiskers show the minimum and maximum values.

For example, in figure 12a, the red box and whisker plot shows the distribution of error for the $0.8 \mathrm{~m}$ targets across all replications, target numbers and velocities for the $0.8 \mathrm{~m}$ height white targets. It was visually interpreted that error was more consistent between target at different heights than at different LiDAR sensor velocity. As the velocity increased, the width of the error distribution increased and there was approximately a $2 \mathrm{~mm}$ increase in mean error as the velocity increased from 0.1 to $2.2 \mathrm{~m} / \mathrm{s}$.

Table 2 provides the height measurement error values averaged across all replications for given actual target heights and LiDAR sensor velocities. The magnitude of average height measurement error across the whole experiment was determined to be $5.3 \mathrm{~mm}$ for the white targets and $0.6 \mathrm{~mm}$ for the black targets. This result was particularly interesting given that the white targets had an average relative intensity of $88.2 \%$ while the black targets had an average relative intensity of $5.4 \%$. While only two target types are likely not enough to quantify a trend in error due to reflectance of the target, it appeared to 
contribute to error, albeit less than the specified accuracy of the LiDAR sensor $( \pm 3 \mathrm{~cm})$.

Table 2: Average height measurement errors of the white and black targets at different LiDAR sensor velocities and target heights.

\begin{tabular}{|c|c|c|c|c|c|c|c|c|c|c|}
\hline \multirow{3}{*}{$\begin{array}{c}\text { Actual Height } \\
(\mathrm{m})\end{array}$} & \multicolumn{5}{|c|}{$\begin{array}{l}\text { Average Height Measurement Error } \\
\text { from White Targets (mm) }\end{array}$} & \multicolumn{5}{|c|}{$\begin{array}{l}\text { Average Height Measurement Error } \\
\text { from Black Targets }(\mathrm{mm})\end{array}$} \\
\hline & \multicolumn{5}{|c|}{ Velocity $(\mathbf{m} / \mathbf{s})$} & \multicolumn{5}{|c|}{ Velocity (m/s) } \\
\hline & 0.1 & 0.5 & 1.0 & 1.5 & 2.2 & 0.1 & 0.5 & 1.0 & 1.5 & 2.2 \\
\hline 0.1 & 6.1 & 8.4 & 7.5 & 7.5 & 9.7 & -0.8 & 1.0 & 2.8 & 1.1 & 2.5 \\
\hline 0.3 & 5.8 & 7.9 & 7.7 & 7.3 & 9.0 & -0.9 & 1.0 & 0.7 & 1.2 & 2.2 \\
\hline 0.5 & 1.0 & 2.7 & 1.8 & 2.2 & 4.7 & -2.0 & -0.2 & -0.5 & -0.6 & 0.3 \\
\hline 0.6 & 3.7 & 4.4 & 5.5 & 4.5 & 4.0 & 0.9 & 1.3 & 1.7 & 2.1 & 1.8 \\
\hline 0.8 & 3.3 & 4.6 & 4.1 & 4.8 & 4.6 & -0.9 & -0.2 & -0.2 & 0.4 & 0.9 \\
\hline
\end{tabular}

The standard deviation of a single target was calculated as the standard deviation of the heights of all the points inside the target ROI. Figure 13 shows the height measurement variability (standard deviation of average height errors for a given treatment) results as box and whisker plots for both height and velocity when measuring the white and black targets.

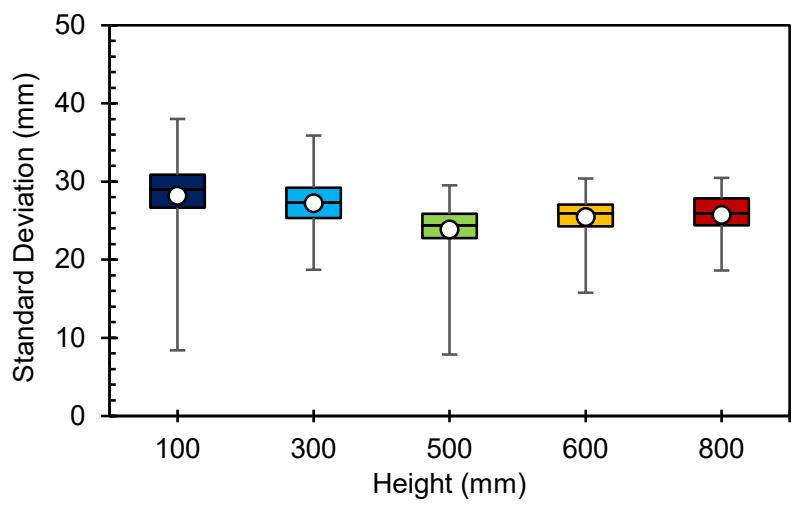

(a)

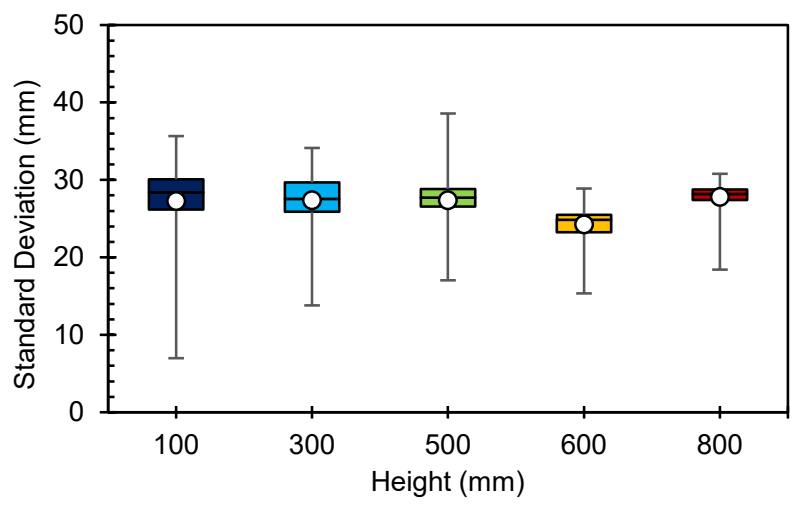

(c)

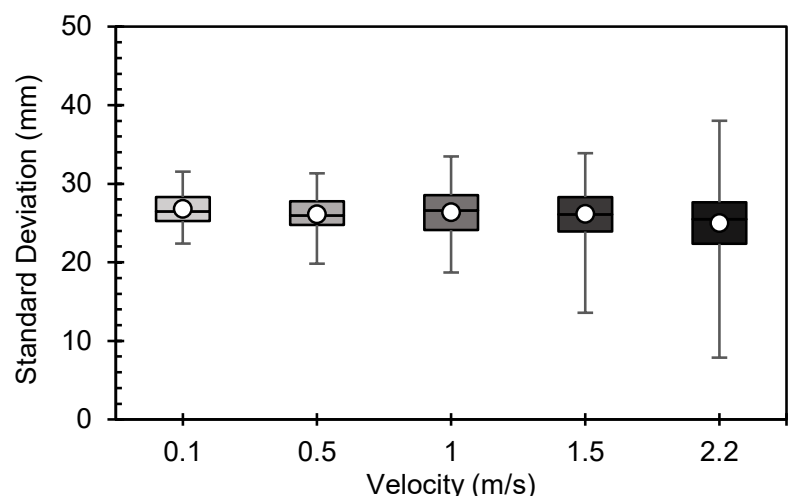

(b)

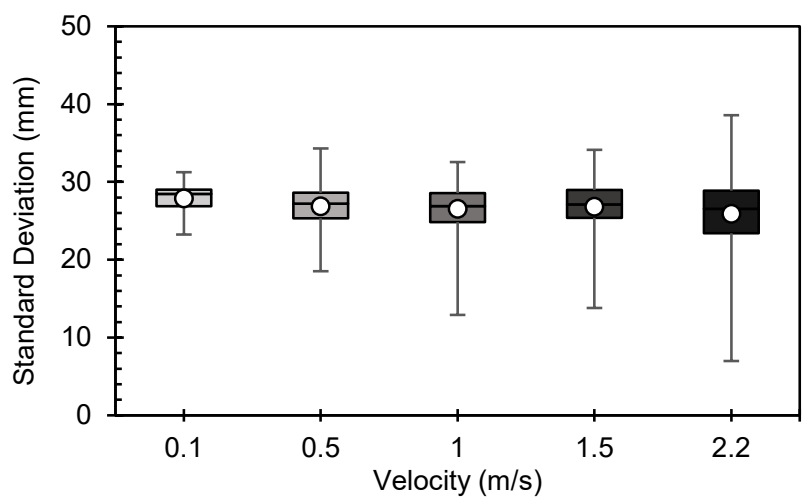

(d)

Figure 13: Box and whisker plots illustrating standard deviation distributions in estimated height for: (a) actual height of white targets; (b) LiDAR sensor velocity when scanning white targets; (c) actual height of black targets and; (d) LiDAR sensor velocity when scanning black targets. Dots and midlines represent the mean and median values, respectively, across all replications of a given target height or velocity. Boxes show the $25 \%$ to $75 \%$ quartile values. Whiskers show the minimum and maximum values.

Maximum and minimum standard deviation in height among replications of a given target height tended to decrease as height of the target increased (distance to the LiDAR sensor decreased). Maximum and minimum standard deviation in height tended to increase as velocity increased. In contrast to height error results, a slight decrease in the mean and median 
standard deviation decreased as the LiDAR sensor velocity increased. Several explanations for this result may exist but the most plausible is that variability in height measurements for a given target (i.e., noise) tends be smaller when fewer measurements are present over a shorter period. In other words, translating a LiDAR sensor over a target slowly to capture a denser point cloud may increase the noise present due to factors not controlled for in this experiment. For instance, there could be differences in accuracy of individual channels in the LiDAR sensor. At slow velocities, all 16 channels will have an opportunity to sweep across a given target and contribute to measurement variability. At high speeds, only a subset of channels collected measurements from a given target, which likely reduced measurement variability. However, error associated with individual LiDAR channels was not assessed in this experiment.

Table 3 provides the standard deviation of the estimated height averaged across all targets and replications for different actual target heights and LiDAR sensor velocities. The average standard deviation across the whole experiment was 26.0 $\mathrm{mm}$ for the white targets and $26.9 \mathrm{~mm}$ for the black targets.

Table 3: Standard deviation of average height measurement errors of the white and black targets at different LiDAR sensor velocities and target heights.

\begin{tabular}{|c|c|c|c|c|c|c|c|c|c|c|}
\hline \multirow{3}{*}{$\begin{array}{c}\text { Actual } \\
\text { Height (m) }\end{array}$} & \multicolumn{5}{|c|}{$\begin{array}{c}\text { Standard Deviation of Average Height Measurement } \\
\text { Error from White Targets (mm) }\end{array}$} & \multicolumn{5}{|c|}{$\begin{array}{l}\text { Standard Deviation of Average Height Measurement } \\
\text { Error from Black Targets (mm) }\end{array}$} \\
\hline & \multicolumn{5}{|c|}{ Velocity $(\mathrm{m} / \mathrm{s})$} & \multicolumn{5}{|c|}{ Velocity $(\mathrm{m} / \mathrm{s})$} \\
\hline & 0.1 & 0.5 & 1.0 & 1.5 & 2.2 & 0.1 & 0.5 & 1.0 & 1.5 & 2.2 \\
\hline 0.1 & 28.7 & 28.1 & 28.6 & 28.6 & 27.8 & 29.4 & 27.4 & 26.2 & 27.6 & 25.8 \\
\hline 0.3 & 27.5 & 26.9 & 27.5 & 27.4 & 27.2 & 29.1 & 27.6 & 27.2 & 27.2 & 28.1 \\
\hline 0.5 & 24.4 & 24.0 & 24.8 & 24.2 & 20.6 & 28.1 & 27.2 & 27.6 & 27.4 & 26.4 \\
\hline 0.6 & 25.2 & 25.4 & 26.0 & 25.9 & 24.8 & 24.9 & 24.4 & 24.2 & 24.1 & 23.6 \\
\hline 0.8 & 25.7 & 25.9 & 25.1 & 25.8 & 24.9 & 28.4 & 28.1 & 27.8 & 28.1 & 26.5 \\
\hline
\end{tabular}

Point density and the intensity values were some of the other important parameters of the LiDAR data studied. The point density of a single target was calculated as the number of points recorded within the boundary of the target. Figure 14a illustrates the point density for the white targets averaged across all targets and replications for different heights versus the LiDAR sensor velocity. As velocity increased, point density decreased following a power series. Figure $14 \mathrm{~b}$ illustrates the point density for the white targets averaged across all the targets and replications for different LiDAR sensor velocities versus the actual target height. Point density increased linearly with increase in height at a given velocity. The linear model resulted in a poorer fit for height than the power series model did for velocity due to the physical structure of the targets. Higher targets obstructed the line-of-sight to lower targets, and the pseudo-random distribution of target heights caused the deviations between the linear model and point density for varying height. The black targets exhibited similar point density results to the white targets and are not shown. 


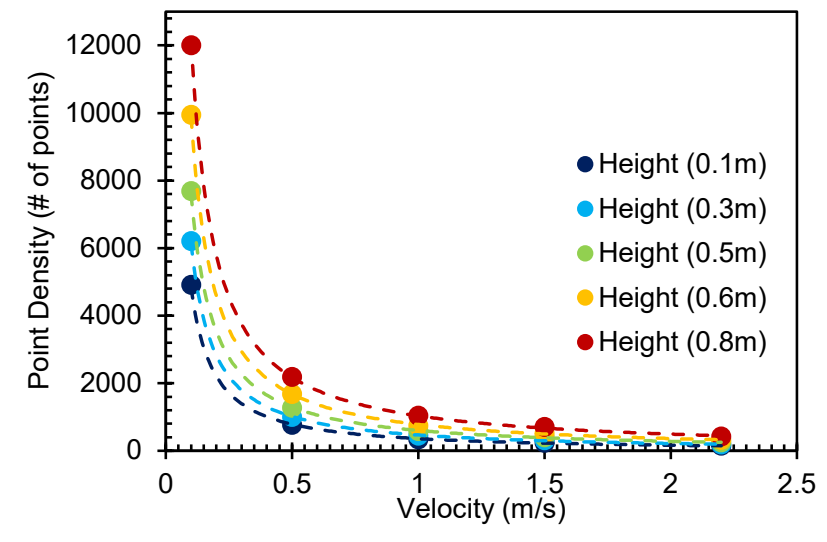

(a)

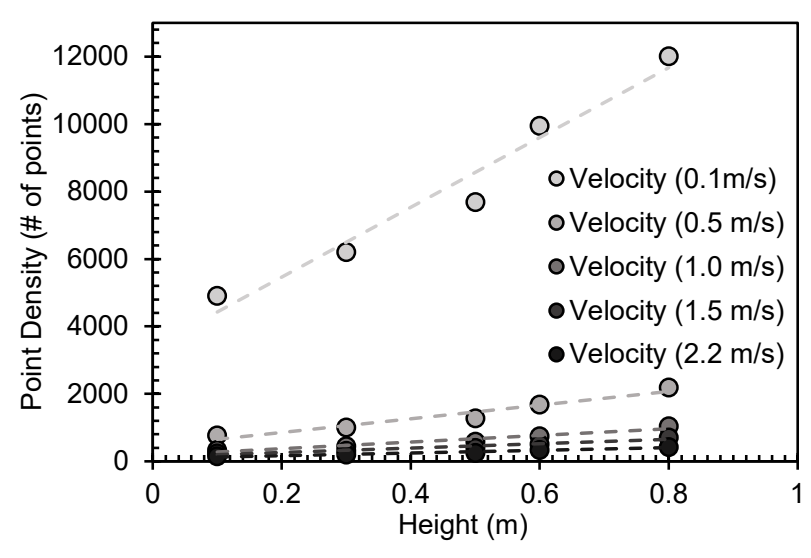

(b)

Figure 14: (a) Relationship between point density and velocity at different heights; (b) Relationship between point density and height at different velocities.

The intensity of a single target was calculated as the average intensity of all the points within the ROI of the target. Table 4 provides the intensity values averaged across all the targets and replications for different velocity profiles and different heights. The average relative intensity value across the whole experiment was $88.2 \%$ for the white targets and $5.4 \%$ for the black targets and didn't deviate substantially with changes in the LiDAR velocity or actual height of a target. The average intensity values were in line with the LiDAR manufacturer's specifications, which defined intensity values of 0 and 100 for perfectly black and perfectly white, respectively.

Table 4: Average intensity values of white and black targets at different heights and velocities.

\begin{tabular}{|c|c|c|c|c|c|c|c|c|c|c|}
\hline \multicolumn{6}{|c|}{ Average Intensity of White Targets (\%) } & \multicolumn{5}{|c|}{ Average Intensity of Black Targets (\%) } \\
\hline \multirow{2}{*}{$\begin{array}{c}\text { Actual } \\
\text { Height } \\
\text { (m) }\end{array}$} & \multicolumn{5}{|c|}{ Velocity $(\mathrm{m} / \mathrm{s})$} & \multicolumn{5}{|c|}{ Velocity $(\mathrm{m} / \mathrm{s})$} \\
\hline & 0.1 & 0.5 & 1.0 & 1.5 & 2.2 & 0.1 & 0.5 & 1.0 & 1.5 & 2.2 \\
\hline 0.1 & 84.7 & 85.2 & 84.8 & 84.9 & 84.9 & 5.9 & 6.1 & 6.0 & 6.6 & 6.3 \\
\hline 0.3 & 89.5 & 90.7 & 90.6 & 90.4 & 88.5 & 5.3 & 5.5 & 5.5 & 5.5 & 5.4 \\
\hline 0.5 & 88.7 & 90.5 & 90.5 & 90.2 & 89.8 & 5.4 & 5.6 & 5.7 & 5.6 & 5.5 \\
\hline 0.6 & 88.9 & 89.6 & 88.5 & 89.0 & 88.9 & 5.3 & 5.4 & 5.4 & 5.4 & 5.3 \\
\hline 0.8 & 86.8 & 87.3 & 88.1 & 88.1 & 85.5 & 4.6 & 4.7 & 4.7 & 4.7 & 4.8 \\
\hline
\end{tabular}

\section{Statistcial Analysis of Test TARget Data}

Statistical analysis was performed to determine if significant differences between average errors and standard deviations existed for different target heights, LiDAR sensor velocities, and target colors. The raw data was read by a SAS script (9.4, SAS, Cary, NC) and was sorted by target height, replication, velocity and target number and averaged across all the data points. The height measurement error was calculated as the difference of estimated and actual target height. Then the height measurement error was modeled with four classes consisting of velocity, target number, replication and actual height. The replication and target number were considered as the random blocks and the target-to-target variability was included in the analysis. The height measurement error was estimated using actual height, velocity, and interaction between actual height and velocity. Table 5 provides the results of the statistical analysis of error prediction of the white targets. 
Table 5: Statistical analysis results of the white targets: (a) Average height measurement error showing the effect of target height and velocity on significance; (b) Tukey grouping table for velocity isolating which means are significantly different.

\begin{tabular}{ccccc}
\hline \multicolumn{5}{c}{ TYPE III Tests of Fixed Effects } \\
\hline Effect & Num & Den DF & F Value & Pr > F \\
\hline Target Height & 4 & 20 & 2.93 & 0.0464 \\
Velocity & 4 & 20 & 4.06 & 0.0143 \\
$\begin{array}{c}\text { Velocity * } \\
\text { Target Height }\end{array}$ & 16 & 680 & 1.36 & 0.1567 \\
\hline
\end{tabular}

(a)

\begin{tabular}{cccc}
\hline \multicolumn{4}{c}{$\begin{array}{c}\text { Tukey-Kramer Grouping for Velocity } \\
\text { Least Squares Means (Alpha=0.05) }\end{array}$} \\
\hline \multicolumn{4}{c}{$\begin{array}{c}\text { LS-means with the same letter } \\
\text { are not significantly different }\end{array}$} \\
\hline Velocity (m/s) & Estimate (mm) & Tukey Grouping \\
\hline 2.2 & 6.4141 & & $\mathrm{~A}$ \\
0.5 & 5.5810 & $\mathrm{~B}$ & $\mathrm{~A}$ \\
1.0 & 5.3101 & $\mathrm{~B}$ & $\mathrm{~A}$ \\
1.5 & 5.2413 & $\mathrm{~B}$ & $\mathrm{~A}$ \\
0.1 & 3.9931 & $\mathrm{~B}$ & \\
\hline
\end{tabular}

(b)

The p-value of the interaction factors (Table 5a) was greater than 0.05 , so the interaction factor was considered insignificant. The velocity had a p-value $<0.05$ making it a significant factor affecting the height measurement error. The p-value of the height factor was slightly less than 0.05 , indicating weak significance. The Tukey grouping table (Table $5 b$ ) was used to detect which values, or groups of values, caused a factor to exhibit significant response. It was found that the error estimates of 0.1 and 2.2 velocities (maximum and minimum velocities tested) were significantly different and the error estimate generally increased as the velocity increased. The Tukey grouping of the height (not shown) did not exhibit any significantly different errors in heights, ruling out target height as the significant factor affecting the height measurement error of the white targets.

The same statistical analysis was repeated for the black targets. Table 6 provides the summary of the statistical analysis of error prediction of the black targets.

Table 6: Statistical analysis results of the black targets: (a) Average height measurement error showing the effect of target height and velocity on significance; (b) Tukey grouping table for velocity isolating which means are significantly different.

\begin{tabular}{ccccc}
\hline \multicolumn{5}{c}{ TYPE III Tests of Fixed Effects } \\
\hline Effect & Num DF & Den DF & F Value & Pr > F \\
\hline Target Height & 4 & 20 & 0.42 & 0.7894 \\
Velocity & 4 & 20 & 4.33 & 0.0110 \\
$\begin{array}{c}\text { Velocity * } \\
\text { Target Height }\end{array}$ & 16 & 680 & 0.79 & 0.7020 \\
\hline
\end{tabular}

(a)

\begin{tabular}{cccc}
\hline \multicolumn{4}{c}{$\begin{array}{c}\text { Tukey-Kramer Grouping for Velocity } \\
\text { Least Squares Means (Alpha=0.05) }\end{array}$} \\
\hline \multicolumn{4}{c}{$\begin{array}{c}\text { LS-means with the same letter } \\
\text { are not significantly different }\end{array}$} \\
\hline Velocity (m/s) & Estimate (mm) & Tukey Grouping \\
\hline 2.2 & 1.6134 & & $\mathrm{~A}$ \\
0.5 & 0.8787 & $\mathrm{~B}$ & $\mathrm{~A}$ \\
1.0 & 0.8347 & $\mathrm{~B}$ & $\mathrm{~A}$ \\
1.5 & 0.5747 & $\mathrm{~B}$ & $\mathrm{~A}$ \\
0.1 & -0.7177 & $\mathrm{~B}$ & \\
\hline
\end{tabular}

(b)

The p-values for both the interaction and actual height were greater than 0.05 (Table 6a), making them both insignificant factors. The velocity was again a significant factor $(p$-value $<0.05)$ affecting the height measurement error. The Tukey 
grouping table (Table 6b) revealed again that there were significant differences between slowest and fastest velocity profiles and the error estimate generally increased as the velocity increased. The slowest velocity profile has a negative error estimate inferring that it underestimated the heights of the black targets whereas the faster velocities have a positive error estimate by overestimating the heights of the black targets.

The standard deviation in height measurements for both white and black targets were analyzed using the same method as the height measurement error. Table 7 summarizes the statistical analysis results of the standard deviation in height estimation of the white targets.

Table 7: Statistical analysis results of the white targets: (a) Standard deviation in average height measurement error showing the effect of target height and velocity on significance; (b) Tukey grouping table for velocity isolating which means are significantly different; (c) Tukey grouping table for height isolating which means are significantly different.

\begin{tabular}{|c|c|c|c|c|c|c|c|c|c|c|c|}
\hline \multicolumn{5}{|c|}{ TYPE III Tests of Fixed Effects } & \multicolumn{3}{|c|}{$\begin{array}{l}\text { Tukey-Kramer Grouping for Velocity } \\
\text { Least Squares Means (Alpha=0.05) }\end{array}$} & \multicolumn{4}{|c|}{$\begin{array}{l}\text { Tukey-Kramer Grouping for Height } \\
\text { Least Squares Means (Alpha=0.05) }\end{array}$} \\
\hline Effect & $\begin{array}{c}\text { Num } \\
\text { DF }\end{array}$ & $\begin{array}{l}\text { Den } \\
\text { DF }\end{array}$ & $\begin{array}{c}\mathbf{F} \\
\text { Value }\end{array}$ & $\operatorname{Pr}>\mathbf{F}$ & \multicolumn{3}{|c|}{$\begin{array}{l}\text { LS-means with the same letter } \\
\text { are not significantly different }\end{array}$} & \multicolumn{4}{|c|}{$\begin{array}{l}\text { LS-means with the same letter } \\
\text { are not significantly different }\end{array}$} \\
\hline $\begin{array}{c}\text { Target Height } \\
\text { Velocity }\end{array}$ & $\begin{array}{l}4 \\
4\end{array}$ & 20 & 10.80 & $\begin{array}{c}0.0357 \\
<0.0001\end{array}$ & $\begin{array}{c}\text { are not } \\
\begin{array}{c}\text { Velocity } \\
(\mathbf{m} / \mathbf{s})\end{array}\end{array}$ & $\begin{array}{c}\text { lificantly d } \\
\text { Estimate } \\
(\mathrm{mm})\end{array}$ & $\begin{array}{l}\text { ferent } \\
\text { Tukey } \\
\text { Grouping }\end{array}$ & $\begin{array}{l}\text { are } \\
\begin{array}{c}\text { Height } \\
\text { (m) }\end{array}\end{array}$ & $\begin{array}{c}\text { significant } \\
\text { Estimate } \\
(\mathrm{mm})\end{array}$ & & $\begin{array}{l}\text { unt } \\
\text { ukey } \\
\text { uping }\end{array}$ \\
\hline \multirow{5}{*}{$\begin{array}{c}\text { Velocity * } \\
\text { Target Height }\end{array}$} & 16 & 680 & 1.10 & 0.3489 & 0.1 & 26.8011 & $\mathrm{~A}$ & 0.1 & 28.2014 & & $\mathrm{~A}$ \\
\hline & & & & & 0.5 & 26.3524 & A & 0.3 & 27.1905 & $\mathrm{~B}$ & A \\
\hline & & & & & 1.5 & 26.1795 & $\mathrm{~A}$ & 0.8 & 25.7138 & B & A \\
\hline & & & & & 1.0 & 26.1131 & A & 0.6 & 25.4516 & B & A \\
\hline & & & & & 2.2 & 24.9717 & $\mathrm{~B}$ & 0.5 & 23.8606 & $\mathrm{~B}$ & \\
\hline
\end{tabular}

(a)

(b)

(c)

The p-value for the interaction was greater than 0.05 , making it insignificant. The $p$-values for the velocities and heights were less than 0.05 , making them significant factors affecting the standard deviation of measured height. The Tukey grouping tables (Table 7b, Table 7c) showed the standard deviation of the fastest velocity was significantly different from the slower ones and the estimate decreased as the velocity increased. Lower point density at faster velocity profiles was the likely reason behind the reduction in standard deviation. From the Tukey grouping table of height (Table 7c), the standard deviation estimate of the $0.5 \mathrm{~m}$ and $0.1 \mathrm{~m}$ targets were significantly different from each other, causing target height to be one of the significant factors of standard deviation. Excluding the $0.5 \mathrm{~m}$ height data resulted in the height factor becoming insignificant.

Table 8 summarizes the same statistical analysis of standard deviation prediction of the black target. 
Table 8: Statistical analysis results of the black targets: (a) Standard deviation in average height measurement error showing the effect of target height and velocity on significance; (b) Tukey grouping table for velocity isolating which means are significantly different; (c) Tukey grouping table for height isolating which means are significantly different.

\begin{tabular}{ccccc}
\hline \multicolumn{5}{c}{ TYPE III Tests of Fixed Effects } \\
\hline Effect & $\begin{array}{c}\text { Num } \\
\text { DF }\end{array}$ & $\begin{array}{c}\text { Den } \\
\text { DF }\end{array}$ & $\begin{array}{c}\text { F } \\
\text { Value }\end{array}$ & Pr > F \\
\hline Target Height & 4 & 20 & 3.07 & 0.0401 \\
Velocity & 4 & 20 & 11.06 & $<0.00$ \\
$\begin{array}{c}\text { Velocity * } \\
\text { Target Height }\end{array}$ & 16 & 680 & 1.21 & 0.2533 \\
\hline
\end{tabular}

(a)

\begin{tabular}{|c|c|c|c|c|c|c|c|}
\hline \multicolumn{4}{|c|}{$\begin{array}{l}\text { Tukey-Kramer Grouping for Velocity } \\
\text { Least Squares Means (Alpha=0.05) }\end{array}$} & \multicolumn{4}{|c|}{$\begin{array}{l}\text { Tukey-Kramer Grouping for Height } \\
\text { Least Squares Means (Alpha=0.05) }\end{array}$} \\
\hline \multicolumn{4}{|c|}{$\begin{array}{l}\text { LS-means with the same letter } \\
\text { are not significantly different }\end{array}$} & \multicolumn{4}{|c|}{$\begin{array}{l}\text { LS-means with the same letter } \\
\text { are not significantly different }\end{array}$} \\
\hline $\begin{array}{l}\text { Velocity } \\
(\mathbf{m} / \mathbf{s})\end{array}$ & $\begin{array}{c}\text { Estimate } \\
(\mathbf{m m})\end{array}$ & $\begin{array}{r}\text { T } \\
\text { Gro }\end{array}$ & ping & $\begin{array}{l}\text { Height } \\
\text { (m) }\end{array}$ & $\begin{array}{l}\text { Estimate } \\
(\mathbf{m m})\end{array}$ & & $\begin{array}{l}\text { key } \\
\text { uping }\end{array}$ \\
\hline 0.1 & 27.8919 & & A & 0.8 & 27.7959 & & $\mathrm{~A}$ \\
\hline 0.5 & 26.8911 & & B & 0.3 & 27.3925 & B & A \\
\hline 1.5 & 26.8210 & $\mathrm{C}$ & B & 0.5 & 27.3618 & B & A \\
\hline 1.0 & 26.5436 & $\mathrm{C}$ & B & 0.1 & 27.2752 & B & A \\
\hline 2.2 & 25.9273 & $\mathrm{C}$ & & 0.6 & 24.2494 & B & \\
\hline
\end{tabular}

(b)

(c)

The p-value for interaction was greater than 0.05 , making it insignificant. The p-values for the velocities and heights were less than 0.05 , making them significant factors affecting the standard deviation of measured height. From the Tukey grouping tables (Table $8 \mathrm{~b}$, Table $8 \mathrm{c}$ ), the standard deviation estimate of the slower velocities were significantly different from the faster ones and the estimate decreased as the velocity increased similar to the white targets. The standard deviation estimate of $0.6 \mathrm{~m}$ target was significantly different than the other heights, resulting in height as one of the significant factors of standard deviation. Excluding the $0.6 \mathrm{~m}$ height data resulted in the height factor becoming insignificant.

Target height was a significant factor only affecting the standard deviation in height measurements. The ROI was smaller in height (y-coordinate) for the $0.5 \mathrm{~m}$ and $0.6 \mathrm{~m}$ targets than the other targets due to being $0.1 \mathrm{~m}$ apart $( \pm 0.05 \mathrm{~m}$ instead of $\pm 0.1 \mathrm{~m})$. The decreased ROI for both the heights was the likely cause of the reduction in standard deviation for the $0.5 \mathrm{~m}$ and $0.6 \mathrm{~m}$ targets relative to the other target heights when measuring white and black targets, respectively.

Finally, a t-test was conducted for the errors between white and black targets across different replications, velocities and heights. Table 9 summarizes t-test results of the errors between the white and black targets.

Table 9: T-test of the errors between white and black targets.

\begin{tabular}{ccccc}
\hline \multicolumn{5}{c}{ Equality of Variances } \\
\hline Method & Num DF & Den DF & F Value & Pr $>$ F \\
\hline Folded F & 749 & 749 & 1.15 & 0.0524 \\
\hline \multicolumn{5}{c}{ Test Statistics } \\
\hline Method & Variances & DF & t Value & Pr $>|\mathbf{t}|$ \\
\hline Pooled & Equal & 1498 & -19.06 & $<0.0001$ \\
\hline Satterthwaite & Unequal & 1490.5 & -19.06 & $<0.0001$ \\
\hline
\end{tabular}

The equality of variances came out to be insignificant concluding that both the white and black targets have an equal variance or distribution of errors. As the variances was determined to be insignificant, the pooled statistic was given the 
priority over Satterthwhite, and was significant as the p-value was less than 0.05 . Thus, target color (intensity) was a significant factor in height measurement error. In contrast to the effects of target height and LiDAR sensor velocity, target color had the most pronounce effect on height measurement error. Black targets produced lower intensity measurements and resulted in smaller average height measurement error than white targets. Further work should be done to determine if the offset in height measurement error can be calibrated based on the reported intensity. This is particularly important for agricultural environments where a wide variety of intensities will likely be present in close proximity to one another.

\section{CONCLUSIONS}

A linear motion system was designed to control the dynamics of a multi-channel LiDAR sensor. The linear motion system performance was validated using a robotic total station and the uncertainty in the dynamics of the LiDAR were determined to be negligible as compared to the LiDAR accuracy.

A test target was fabricated to determine the effects of target height and LiDAR velocity on the accuracy and precision of height measurements. Results showed the trend of accuracy of the LiDAR over a test target at different velocities and different heights. Height measurement error increased as the velocity increased, concluding that accuracy decreased as the velocity increased. The variability of error in height measurements also increased as the velocity of the LiDAR increased. Although the statistical analysis showed a significant difference between the faster and slower velocity profiles, the difference was approximately $1 \mathrm{~mm}$ over the range of target heights and LiDAR velocities tested. The standard deviation estimate followed an opposite trend, as the velocity increased the standard deviation decreased by approximately $1 \mathrm{~mm}$ over the range of target heights and LiDAR velocities tested. Statistical analysis showed a significant difference in standard deviation of height measurements between faster and slower velocity profiles. Future work should investigate the error associated with individual LiDAR channels to determine if the reduction in standard deviation in height measurements was a result of measurements from fewer channels when traveling at higher velocities.

In total, these results conclude that the small changes in target height and LiDAR velocity will affect the accuracy and precision of LiDAR measurements. The effect is small and may not be substantial for agricultural applications, where other sources of error, such as moving crop canopies or error in resolving position of the sensor are more likely to dominate overall measurement error. The velocity of the LiDAR will be a tradeoff variable with lower velocities having higher point densities, higher variability, and higher post-processing times, and with higher velocities having lower point densities, lower variability, and lower post-processing time. Intensity of the LiDAR measurement for a given target resulted in the largest change in measurement error, which was a particularly important result for agricultural applications where the measurement intensities from crops and soils will likely vary over a wide range. Field data showing typical reflectance intensities of 
agricultural materials could be used in future experiments to develop test targets with more practical reflectance properties. More complicated geometries should also be considered for future work that better reflect the physical nature of agricultural targets.

\section{ACKNOWLEDGEMENTS}

This work is supported by the National Institute of Food and Agriculture, U.S. Department of Agriculture, under award number 2016-70005-25648 and through the Hatch/Multistate Program under Grant No. 1015710. Special thanks to Eric Roemmele at the University of Kentucky Applied Statistics Lab for statistical analysis assistance. Special thanks to Lee Rechtin and Edward Hutchens at the University of Kentucky Agricultural Machinery Research Laboratory for their help with the fabrication of the linear motion system.

\section{REFERENCES}

Arnó, J., Escolà, A., Vallès, J. M., Llorens, J., Sanz, R., Masip, J., Palacín, J., \& Rosell-Polo, J. R. (2013). Leaf area index estimation in vineyards using a ground-based LiDAR scanner. Precision Agriculture, 14(3), 290-306. doi:https://doi.org/10.1007/s11119-012$\underline{9295-0}$

Bonan, G. B. (1993). Importance of leaf area index and forest type when estimating photosynthesis in boreal forests. Remote Sensing of Environment, 43(3), 303-314. doi:https://doi.org/10.1016/0034-4257(93)90072-6

Colaço, A. F., Trevisan, R. G., Molin, J. P., Rosell-Polo, J. R., \& Escolà, A. (2017). Orange tree canopy volume estimation by manual and LiDAR-based methods. Advances in Animal Biosciences, 8(2), 477-480. doi:https://doi.org/10.1017/S2040470017001133

Cui, Y., Zhao, K., Fan, W., \& Xu, X. (2010, 25-30 July 2010). Using airborne LiDAR to retrieve crop structural parameters. Paper presented at the IEEE International Geoscience and Remote Sensing Symposium.

Dworak, V., Selbeck, J., \& Ehlert, D. (2011). Ranging sensors for vehicle-based measurement of crop stand and orchard parameters: A review. Transactions of the ASABE, 54(4), 1497. doi:https://doi.org/10.13031/2013.39013

Estornell, J., Ruiz, L. A., Velázquez-Martí, B., \& Fernández-Sarría, A. (2011). Estimation of shrub biomass by airborne LiDAR data in small forest stands. Forest Ecology and Management, 262(9), 1697-1703. doi:https://doi.org/10.1016/j.foreco.2011.07.026

Guo, T., Kujirai, T., \& Watanabe, T. (2012). Mapping crop status from an unmanned aerial vehicle for precision agriculture applications. Int. Arch. Photogramm. Remote Sens. Spatial Inf. Sci., XXXIX-B1, 485-490. doi:https://doi.org/10.5194/isprsarchives-XXXIX-B1$\underline{485-2012}$

Kelly, M., \& Di Tommaso, S. (2015). Mapping forests with LiDAR provides flexible, accurate data with many uses. California Agriculture, 69(1), 14-20. doi:http://dx.doi.org/10.3733/ca.v069n01p14

Lefsky, M. A., Cohen, W. B., Parker, G. G., \& Harding, D. J. (2002). LiDAR remote sensing for ecosystem studies: LiDAR, an emerging remote sensing technology that directly measures the three-dimensional distribution of plant canopies, can accurately estimate vegetation structural attributes and should be of particular interest to forest, landscape, and global ecologists. BioScience, 52(1), 19- 
30. doi:http://dx.doi.org/10.1641/0006-3568(2002)052[0019:LRSFES]2.0.CO;2

Lin, Y. (2015). LiDAR: An important tool for next-generation phenotyping technology of high potential for plant phenomics? Computers and electronics in Agriculture, 119, 61-73. doi:https://doi.org/10.1016/j.compag.2015.10.011

Malveaux, C., G Hall, S., \& Price, R. (2014). Using drones in agriculture: Unmanned aerial systems for agricultural remote sensing applications. Paper presented at the 2014 Montreal, Quebec Canada July 13 - July 16, 2014, St. Joseph, MI. http://elibrary.asabe.org/abstract.asp?aid $=44960 \& \mathrm{t}=5$

Mathanker, S. K., Maughan, J. D., Hansen, A. C., Grift, T. E., \& Ting, K. C. (2014). Sensing Miscanthus Swath Volume for Maximizing Baler Throughput Rate. Transactions of the ASABE, 57(2), 355-362. doi:https://doi.org/10.13031/trans.57.10167

Nie, S., Wang, C., Dong, P., Xi, X., Luo, S., \& Zhou, H. (2016). Estimating leaf area index of maize using airborne discrete-return LiDAR data. IEEE Journal of Selected Topics in Applied Earth Observations and Remote Sensing, 9(7), 3259-3266. doi:https://doi.org/10.1109/JSTARS.2016.2554619

Pittman, J., Arnall, D., Interrante, S., Moffet, C., \& Butler, T. (2015). Estimation of biomass and canopy height in bermudagrass, alfalfa, and wheat using ultrasonic, laser, and spectral sensors. Sensors, 15(2), 2920. doi:https://doi.org/10.3390/s150202920

Sanz-Cortiella, R., Llorens-Calveras, J., Escolà, A., Arnó-Satorra, J., Ribes-Dasi, M., Masip-Vilalta, J., Camp, F., Gràcia-Aguilá, F., Solanelles-Batlle, F., Planas-DeMartí, S., Pallejà-Cabré, T., Palacin-Roca, J., Gregorio-Lopez, E., Del-Moral-Martínez, I., \& RosellPolo, J. R. (2011). Innovative LiDAR 3D dynamic measurement system to estimate fruit-tree leaf area. Sensors, 11(6), 5769. doi:https://doi.org/doi:10.3390/s110605769

Stamatiadis, S., Tsadilas, C., \& Schepers, J. S. (2010). Ground-based canopy sensing for detecting effects of water stress in cotton. Plant and Soil, 331(1), 277-287. doi:https://doi.org/10.1007/s11104-009-0252-2

Sun, S., Li, C., Paterson, A. H., Jiang, Y., Xu, R., Robertson, J. S., Snider, J. L., \& Chee, P. W. (2018). In-field high throughput phenotyping and cotton plant growth analysis using LiDAR. Frontiers in Plant Science, 9, 16. doi:https://doi.org/10.3389/fpls.2018.00016

Vázquez-Arellano, M., Griepentrog, H., Reiser, D., \& Paraforos, D. (2016). 3-D imaging systems for agricultural applications-A review. Sensors, 16(5), 618. doi:https://doi.org/10.3390/s16050618

Weiss, U., \& Biber, P. (2011). Plant detection and mapping for agricultural robots using a 3D LIDAR sensor. Robotics and autonomous systems, 59(5), 265-273. doi:https://doi.org/10.1016/j.robot.2011.02.011

Zhang, C., \& Kovacs, J. M. (2012). The application of small unmanned aerial systems for precision agriculture: A review. Precision Agriculture, 13(6), 693-712. doi:https://doi.org/10.1007/s11119-012-9274-5

Zhang, L., \& Grift, T. E. (2012). A LIDAR-based crop height measurement system for Miscanthus giganteus. Computers and electronics in Agriculture, 85, 70-76. doi:https://doi.org/10.1016/i.compag.2012.04.001 